\title{
Histone Deacetylase Activity Is Necessary for Oligodendrocyte Lineage Progression
}

\author{
Mireya Marin-Husstege, Michela Muggironi, Aixiao Liu, Patrizia Casaccia-Bonnefil \\ Department of Neuroscience and Cell Biology, University of Medicine and Dentistry of New Jersey, R. Wood Johnson \\ Medical School, Piscataway, New Jersey 08854
}

Gene expression can be modulated by chromatin changes induced by histone acetylation and deacetylation. Acetylation of histone lysine residues by acetyltransferases is associated with transcriptionally active chromatin, whereas the removal of acetyl groups by histone deacetylases (HDACs) correlates with repressed chromatin. Recent evidence has shown that histone deacetylation is responsible for restricting neuronal gene expression, whereas histone acetylation is necessary for astrocytic differentiation We now asked whether histone acetylation or deacetylation was necessary for oligodendrocyte differentiation. Neonatal rat cortical progenitors were kept proliferating and undifferentiated in the presence of mitogens and induced to stop proliferating and differentiate into oligodendrocytes by mitogen removal. Histone deacetylation was observed during the temporal window between exit from the cell cycle and onset of differentiation, which was characterized by acquisition of

The complexity of the mammalian brain results from the activation of genetic differentiation programs leading to three distinct cell types: neurons, astrocytes, and oligodendrocytes. Our laboratory has been interested in defining the mechanisms responsible for oligodendrocyte differentiation and their relationship to cell cycle exit. Several studies have shown that progenitors remain undifferentiated when cultured in the presence of mitogens and differentiate into oligodendrocytes in response to mitogen withdrawal (Noble and Murray, 1984; Temple and Raff, 1985; Gard and Pfeiffer, 1993; Bansal and Pfeiffer, 1997). This suggested the existence of an obligate relationship between cell cycle exit and oligodendrocyte differentiation. Furthermore, the defective differentiation observed in oligodendrocyte progenitors isolated from mice with targeted deletion of genes encoding for cell cycle inhibitors (Casaccia-Bonnefil et al., 1997; Durand et al., 1998; Zezula et al., 2001) reinforced this concept and suggested that cell cycle exit was the driving force for differentiation. This hypothesis was tested by overexpressing specific cell cycle inhibitors in proliferating progenitors (Tikoo et al., 1998; Tang et al., 1999). Although proliferation stopped by increasing the levels of cell cycle inhibitors, progenitors were unable to progress to oli-

\footnotetext{
Received May 21, 2002; revised Aug. 30, 2002; accepted Sept. 13, 2002.

This work was supported by the Wadsworth Foundation (P.C.B.) and National Multiple Sclerosis Society Grants RG 3154-A-2 (P.C.B.) and FA 1512-A-1 (M.M.H.). We thank Drs. N. Hayes and E. Di Cicco-Bloom for critical reading of this manuscript, Dr. D. Reinberg for advice and reagents, and Dr. M. Bustin for antibodies.

Correspondence should be addressed to Patrizia Casaccia-Bonnefil, Department of Neuroscience and Cell Biology, University of Medicine and Dentistry of New Jersey, 675 Hoes Lane, Piscataway, NJ 08854. E-mail: casaccpa@umdnj.edu. Copyright (C) 2002 Society for Neuroscience 0270-6474/02/2210333-13\$15.00/0
}

branched morphology and myelin gene expression. Blocking HDAC activity during this critical window using the inhibitor trichostatin A (TSA) prevented the progression of progenitors into mature oligodendrocytes. TSA-treated progenitors were able to exit from the cell cycle but did not progress to oligodendrocytes. Their development was arrested at the progenitor stage, characterized by simple morphology and lack of myelin gene expression. The effect of TSA on progenitor differentiation was lineage specific, because TSA did not affect the ability of these cells to differentiate into type II astrocytes when cultured in the presence of serum. From these data, we conclude that histone deacetylation is a necessary component of the oligodendrocyte differentiation program.

Key words: myelin; differentiation; transcription; trichostatin A; chromatin; development

godendrocytes. Together, these studies suggested that cell cycle exit was necessary, but not sufficient, to induce differentiation.

Because the proliferative state of a cell is associated with changes of chromatin components, we asked whether modification of nucleosomal histones, the basic unit of chromatin, would be a necessary element for the activation of the oligodendrocyte differentiation program. Nucleosomes are composed of a core octamer of histones called H2A, H2B, H3, and H4, and 146 base pairs of DNA are wrapped around them. The N-terminal tail of nucleosomal histones is rich in lysine residues, which are targets for acetyltransferases (HATs) and histone deacetylases (HDACs) (Csordas, 1990). Acetylation of these lysine residues represents a very efficient way to loosen the interaction between histones and DNA and is generally associated with active transcription (Ashraf and Ip, 1998; Struhl, 1998). Conversely, deacetylation of lysine residues favors compaction of chromatin, making the access of the transcriptional apparatus to nearby promoters more difficult and therefore decreasing promoter basal activity (Jeong and Stein, 1994; Roth and Allis, 1996; Svaren and Horz, 1996).

Recruitment of the histone deacetylase activity HDAC to the promoter of neuronal genes has been shown to be essential for the repression of these genes in non-neuronal cells (Chong et al., 1995; Schoenherr and Anderson, 1995). A transcriptional factor called REST is responsible for repressing the neuronal phenotype by recruiting a large complex containing the HDAC and other repressors to negative regulatory cis-elements (RE-1) in the promoter of neuronal-specific genes (Ballas et al., 2001). Decreased expression of REST in postmitotic neurons results in the disruption of these chromatin modifier complexes and allows expression of neuronal genes (Griffith et al., 2001). 
Conversely, recruitment of other chromatin modifiers, such as the p300 histone acetyltransferase, has been involved in the differentiation of astrocytes or neurons from neural stem cells (Nakashima et al., 1999; Sun et al., 2001). During astrocytic differentiation, for instance, p300 is part of a complex with other transcriptional activators, and the complex is responsible for the activation of the expression of glial fibrillary protein (GFAP) (Nakashima et al., 1999). Similarly, in differentiating neurons, p300 is part of a complex with general transcription factors and neurogenins, and this complex activates the expression of neuralspecific genes, such as NeuroD (Sun et al., 2001)

We now asked whether histone acetylation is also part of the mechanism responsible for the differentiation of oligodendrocyte progenitors.

\section{MATERIALS AND METHODS}

Antibodies. Antibodies against histones $\mathrm{H} 3, \mathrm{H} 4, \mathrm{H} 2 \mathrm{~A}$, and $\mathrm{H} 2 \mathrm{~B}$ were purchased from Santa Cruz Biotechnology (Santa Cruz, CA), anti-acetyl lysine and acetylated histones $\mathrm{H} 3$ and $\mathrm{H} 4$ were from Upstate Biotechnology (Lake Placid, NY), anti-HMGN1 (high-motility group N 1) and anti-HMGN2 were kindly provided by Dr. M. Bustin (Laboratory of Medicinal Chemistry, National Cancer Institute, National Institutes of Health, Bethesda, MD), anti-actin antibodies were from Sigma (St. Louis, MO), anti-GalC was from Cedar Lane (Ontario, Canada), and anti-bromodeoxyuridine (BrdU) and anti-GFAP were from Dako (Carpinteria, CA). A2B5 or O4 antibodies were generated from hybridoma cells provided by Dr. R. Bansal (University of Connecticut, Farmington, CT), whereas the antibody against proteolipid protein (PLP) was a gift from Dr. K. Nave (Max Planck Institute, Gottingen, Germany). Secondary antibodies for Western blots were obtained from Promega (Madison, WI). Secondary antibodies conjugated to fluorescein and rhodamine used for immunohistochemistry were obtained from Southern Biotechnologies (Birmingham, AL), Amersham Biosciences (Piscataway, NJ), Jackson ImmunoResearch (West Grove, PA), and Vector Laboratories (Burlingame, CA).

Cell culture. Oligodendrocyte progenitors were isolated from the cortex of postnatal day 1 rats and cultured according to McCarthy and de Vellis (1980). Cells were maintained proliferating and undifferentiated by the addition of basic FGF (bFGF) $(20 \mathrm{ng} / \mathrm{ml})$ in Sato medium (DMEM, $100 \mu \mathrm{g} / \mathrm{ml}$ albumin, $100 \mu \mathrm{g} / \mathrm{ml}$ apo-transferrin, $16 \mu \mathrm{g} / \mathrm{ml}$ putrescine, $0.06 \mathrm{ng} / \mathrm{ml}$ progesterone, $40 \mathrm{ng} / \mathrm{ml}$ selenium, $5 \mu \mathrm{g} / \mathrm{ml}$ insulin, $1 \mathrm{~mm}$ sodium pyruvate, $2 \mathrm{~mm}$ L-glutamine, $100 \mathrm{U} / \mathrm{ml}$ penicillin, and 100 $\mu \mathrm{g} / \mathrm{ml}$ streptomycin). The removal of bFGF from the medium (mitogen withdrawal) was considered as the start of differentiation.

Trichostatin A treatment and BrdU incorporation. Cells were cultured in the presence of bFGF and then induced to differentiate for different time intervals by removing the mitogen from the medium in the presence or absence of trichostatin A (TSA) (Sigma). Typically, TSA was used at a concentration of $10 \mathrm{ng} / \mathrm{ml}$ in all of the experiments, except for the dose-response experiment when $0.1,1$, and $10 \mathrm{ng} / \mathrm{ml}$ were tested. The effect of TSA treatment on the ability of the cell to synthesize DNA (S phase) was evaluated by labeling with $10 \mu \mathrm{M}$ BrdU (Sigma) during the 6 $\mathrm{hr}$ before the end of the experiment. Labeling experiments, therefore, was started at time 0 for the $6 \mathrm{hr}$ sample, at $6 \mathrm{hr}$ for the $12 \mathrm{hr}$ sample, at $18 \mathrm{hr}$ for the $24 \mathrm{hr}$ sample, and at $42 \mathrm{hr}$ for the $48 \mathrm{hr}$ sample. At the indicated times, cells were fixed with $4 \%$ paraformaldehyde and processed for immunocytochemistry. Cells synthesizing DNA were identified by positive immunoreactivity for $\mathrm{BrdU}$ as described previously (Casaccia-Bonnefil et al., 1997, 1999).
Figure 1. Histone deacetylation during oligodendrocyte differentiation. $A$, Schematic representation of oligodendrocyte lineage progression. Oligodendrocyte progenitors can be isolated from the cortex of neonatal rats and cultured in the presence of mitogens. In these conditions, cells have a simple morphology and express the A2B5 marker for early progenitors and the $\mathrm{O} 4$ marker for late progenitors. After removal of mitogens from the culture medium, cells exit from the cell cycle, elaborate secondary and tertiary branches, and, between 48 and $72 \mathrm{hr}$, begin synthesis of GalC, the major lipid constituent of myelin. After $96 \mathrm{hr}$ from the removal of mitogens, cells express high levels of the protein constituent of myelin, PLP. $B$, Time course of protein deacetylation during oligodendrocyte development. Protein lysates were obtained from proliferating progenitors cultured in the presence of bFGF $(0)$, from cells cultured for $6(6), 24(24)$, or $48(48) \mathrm{hr}$ in the absence of bFGF, and from cells treated for $24 \mathrm{hr}$ with $10 \mathrm{ng} / \mathrm{ml}$ TSA in medium without bFGF. After SDS-PAGE and transfer onto nitrocellulose, the blots were probed with antibodies anti-acetyl lysine, and the bands were visualized by chemiluminescence. The size of the molecular weight markers is indicated on the left. The intensity of the chemiluminescent signal reflects the acetylation level. Reprobing the blots with anti-actin antibodies was used as loading control. $C$, Densitometric analysis of histone acetylation. Western blot analysis was performed as described in $B$ using four different cellular preparations. The results of the four experiments were then scanned with a densitometer, quantitated, normalized, and represented as a bar graph. Briefly, the intensity of the signal of each band was measured and normalized by the actin content. The signal of the band detected in progenitors cultured in bFGF was arbitrarily chosen as $100 \%$ value, and the acetylation of each sample was referred to as a percentage of that value.

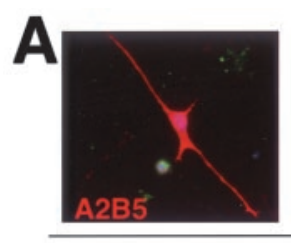

0
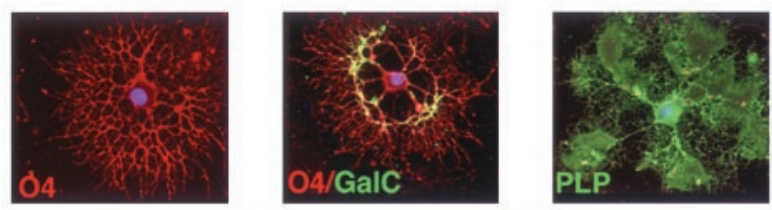

24

48 96

BRANCHING mitogen withdrawal (hrs)

CELL CYCLE EXIT

SYNTHESIS LATE DIFFERENTIATION MARKERS
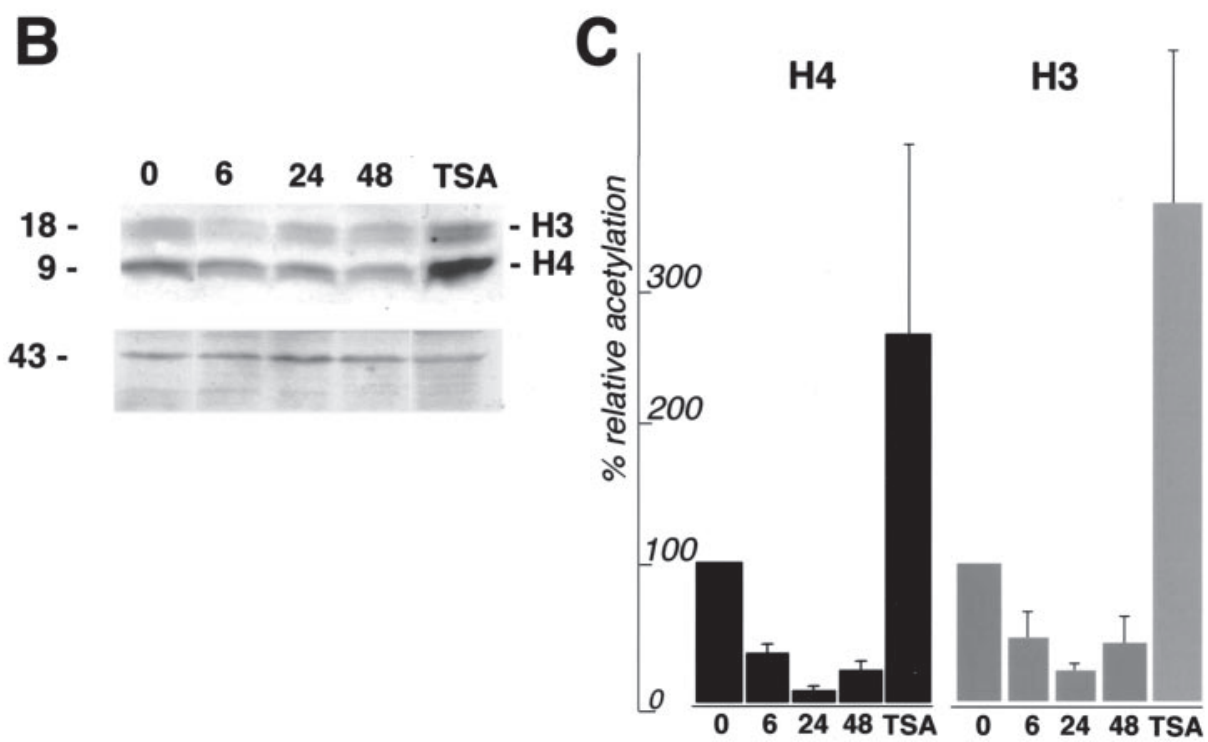
Immunoprecipitation and Western blot analysis. Whole cell lysates were prepared from proliferating progenitors (cultured in bFGF) or from differentiating cells $(6,24$, and $48 \mathrm{hr}$ after mitogen withdrawal). Cells were lysed in a buffer containing $50 \mathrm{~mm}$ HEPES, pH 7.0, $250 \mathrm{~mm} \mathrm{NaCl}$, $0.15 \%$ Nonidet P-40, $1 \mathrm{~mm}$ DTT, $1 \mathrm{mM}$ EDTA, 0.01\% PMSF, $1 \mathrm{~mm}$ aprotinin, and $1 \mathrm{~mm}$ leupeptin (Zhang et al., 2000) for $15 \mathrm{~min}$ on ice. Lysates were further disrupted by serial passages through syringes equipped with different sized needles (18G11/2, 22G11/2, and 26G3/8), followed by sonication on ice at the highest output (three times, $30 \mathrm{sec}$ each, cells were kept on ice for $30 \mathrm{sec}$ between each pulse). Equal amounts of protein $(150 \mu \mathrm{g})$ were separated on a $15 \%$ SDS-PAGE and transferred, at $30 \mathrm{~V}$ for $16-18 \mathrm{hr}$, onto a $0.22 \mu \mathrm{m}$ nitrocellulose membrane using a buffer containing $25 \mathrm{~mm}$ Tris base, $192 \mathrm{~mm}$ glycine, $20 \% \mathrm{v} / \mathrm{v}$ methanol, and $0.04 \%$ SDS, pH 8.3. Western blot analysis was performed as reported previously (Casaccia-Bonnefil et al., 1996, 1997, 1999) using the appropriate dilutions of primary and secondary antibodies. Equal protein loading was guaranteed by probing the blots with anti-actin antibodies. For protein immunoprecipitation experiments, equal amounts of protein $(150 \mu \mathrm{g})$ were immunoprecipitated for $16-18 \mathrm{hr}$ at $4^{\circ} \mathrm{C}$ using $1 \mu \mathrm{g}$ of anti-acetyl lysine antibodies (Upstate Biotechnology). Proteins were separated by SDS-PAGE and transferred to nitrocellulose membrane, as described above, followed by Western blot analysis with antibodies against histone H3 (FL-136; Santa Cruz Biotechnology), histone H4 (H-97; Santa Cruz Biotechnology), histone H2A (H-124; Santa Cruz Biotechnology), histone H2B (FL-126; Santa Cruz Biotechnology), or antiserum against HMGN1 and HMGN2 (Dr. M. Bustin). Immunoreactive bands were visualized using HRP-conjugated secondary antibodies, followed by chemiluminescence. Typically, three to four separate experiments were conducted using cell lysates obtained from three different culture preparations. Changes in protein acetylation were evaluated by scanning the acetylated bands and the actin band with a densitometer (model 300A; Molecular Dynamics, Sunnyvale, CA) and normalizing proteins by actin content. The acetylation of the bands observed in the presence of mitogens was considered as $100 \%$, and the values obtained for each of the other time points were described as a percentage of this value.

Reverse transcription-PCR. Total RNA was isolated using a RNeasy Mini kit (Qiagen, Hilden, Germany); $1.5 \mu \mathrm{g}$ of total RNA was used in 40 $\mu \mathrm{l}$ of reverse transcription (RT) reaction, using a GeneAmp RT-PCR kit (Roche Products, Hertforshire, UK). The RT-PCR was performed in a $20 \mu \mathrm{l}$ reaction mixture containing $2 \mu \mathrm{l}$ of cDNA as template and $0.1 \mu \mathrm{M}$ specific oligonucleotide primer pair. Cycle parameters were $30 \mathrm{sec}$ at $94^{\circ} \mathrm{C}, 30 \mathrm{sec}$ at $50^{\circ} \mathrm{C}$, and $1.5 \mathrm{~min}$ at $72^{\circ} \mathrm{C}$ for 22 cycles. The following oligonucleotide DNA primers were used: for rat $P L P$, the $5^{\prime}$ primer was 5'-GGGTTTGTTAGAGTGCTGTGCTA-3', and the 3' was 5'-CCATGAGTTTAAGGACGGCAA-3'; for rat ceramyl-galactosyl transferase $(C G T)$ the 5' primer was 5'-GGAGTGCTGTTGGAATAGCAA-3', and the $3^{\prime}$ was $5^{\prime}$-CGTACTCCTAGAACACAGACTT- $3^{\prime}$; for rat $\beta$-actin, the $5^{\prime}$ primer was $5^{\prime}$-TGGAATCCTGTGGCATCC-3' and the $3^{\prime}$ primer was 5'-TCGTACTCCTGCTTGCTG-3'; and for p21, the $5^{\prime}$ primer was 5'-GTCCGATCCTGGTGATGTCCGA-3' and the $3^{\prime}$ was 5'-GCTTTCTCTTGCAGAAGACCAA-3'.

Immunocytochemistry. Cells were grown on Permanox chambers for all immunocytochemistry. For oligodendrocyte lineage markers as A2B5, O4, and GalC, coverslips were rinsed gently with PBS (10 mM sodium phosphate, $\mathrm{pH} 7.4$, and $150 \mathrm{~mm} \mathrm{NaCl}$ ) and incubated with hybridoma supernatant (diluted $1: 1$ ) for $30 \mathrm{~min}$ at $37^{\circ} \mathrm{C}$. The cells were then fixed with $4 \%$ paraformaldehyde for $20 \mathrm{~min}$ at room temperature. For staining with antibodies against PLP or GFAP, the fixed cells were first incubated in blocking solution $(0.1 \mathrm{M}$ phosphate buffer, $0.1 \%$ gelatin, $1 \%$ bovine serum albumin, and $0.002 \%$ sodium azide) with $10 \%$ normal goat serum (NGS) (Vector Laboratories) and then typically incubated overnight in primary antibody diluted 1:1000. After incubation with the biotinylated secondary (1:200) for $1 \mathrm{hr}$ at room temperature, immunolabeled cells were visualized using avidin conjugated with specific fluorochromes (diluted 1:500). For double immunocytochemistry with anti-BrdU antibodies, after staining, the first antibody cells were treated with $2 \mathrm{~N} \mathrm{HCl}$ for $10 \mathrm{~min}$ at room temperature, followed by neutralization in $0.1 \mathrm{M}$ sodium borate, $\mathrm{pH} 8.6$, for $10 \mathrm{~min}$, and then they were incubated in anti-BrdU $(1: 100)$. Cells on the chamber slides were counterstained with $4^{\prime}, 6^{\prime}$ diamidino-2-phenylindole (DAPI) (1:1000; Molecular Probes, Eugene, OR) to visualize cell nuclei. Labeled cells were counted in at least three fields, from two or three different experiments performed in duplicate, at $40 \times$ using an inverted fluorescence microscope (Leica, Nussloch, Germany). Cells were counted and classified according to one of the following morphologies: simple, cells are either bipolar or stellate composed exclusively of short primary branches; intermediate, defined by the presence of very long primary branches and or secondary branches; or complex morphology, defined by the presence of tertiary branches. The relative contribution of each category to the whole cell population was calculated, statistically analyzed, and represented in a graph.
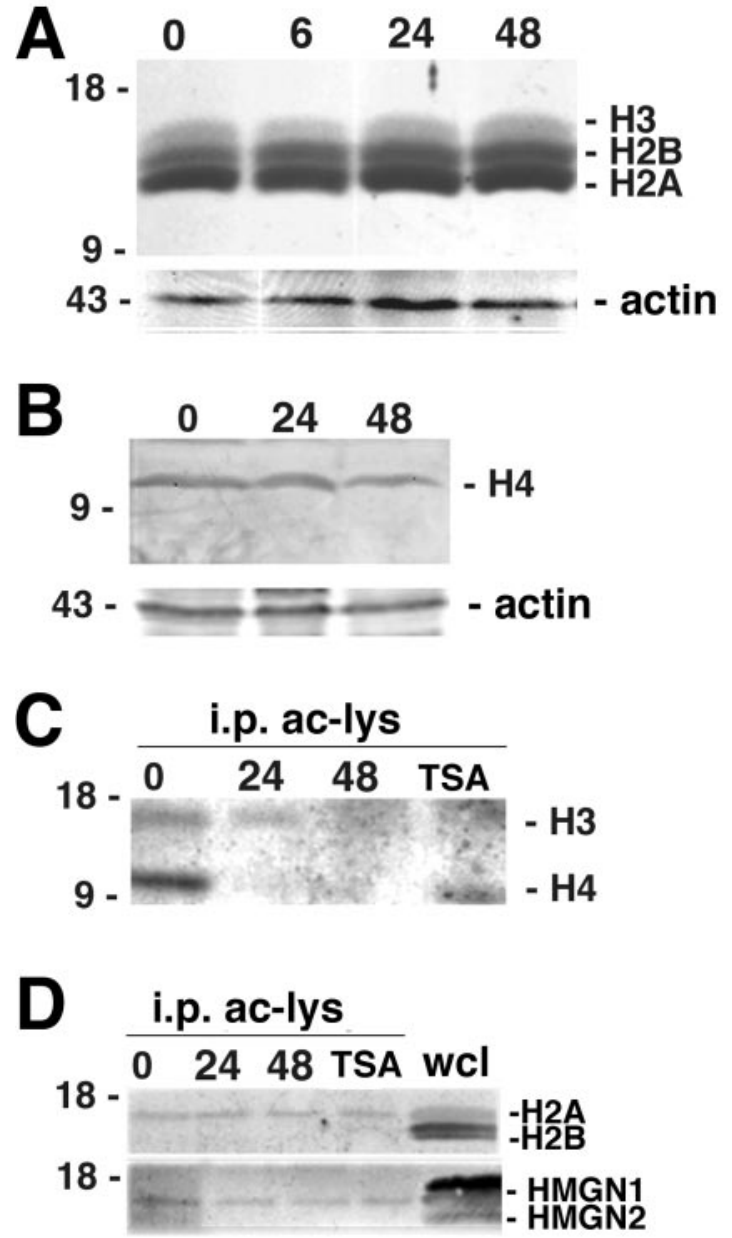

Figure 2. Changes in chromatin components during oligodendrocyte lineage progression. $A$, The steady-state levels of histones $\mathrm{H} 2 \mathrm{~A}, \mathrm{H} 2 \mathrm{~B}$, and $\mathrm{H} 3$ do not change during oligodendrocyte lineage progression. Protein lysates were obtained from proliferating progenitors cultured in bFGF $(0)$ and from cells cultured for $6(6), 24(24)$, or 48 (48) hr in the absence of this mitogen. After separation by electrophoresis, the blots were probed with a mixture of three antibodies recognizing total histones $\mathrm{H} 3, \mathrm{H} 2 \mathrm{~A}$, and $\mathrm{H} 2 \mathrm{~B}$. Controls for loading of proteins were obtained probing the same blot for actin. $B$, The steady-state levels of histone $\mathrm{H} 4$ do not change during oligodendrocyte lineage progression. Protein lysates were obtained from proliferating progenitors cultured in bFGF $(0)$ and from cells cultured for $6(6), 24(24)$, or $48(48) \mathrm{hr}$ in the absence of this mitogen. After separation by electrophoresis, the blots were probed with antibodies recognizing total histone $\mathrm{H} 4$. Reprobing with actin was used as loading control. $C$, Histones $\mathrm{H} 3$ and $\mathrm{H} 4$ are deacetylated. Protein lysates isolated from progenitor cells cultured in the presence of bFGF $(0)$ or in the absence of mitogens for 24 or $48 \mathrm{hr}$, with $(T S A)$ or without $(24,48)$ trichostatin A, were immunoprecipitated using anti-acetyl lysine antibodies (i.p. ac-lys). The blots were probed using anti-histone $\mathrm{H} 3$ and antihistone $\mathrm{H} 4$ antibodies. D, Histone H2A and HMGN1 are deacetylated. Protein lysates were obtained from cells cultured in the conditions described in $C$. Samples were immunoprecipitated using antibodies recognizing acetyl lysine residues and then probed with anti-H2A, $-\mathrm{H} 2 \mathrm{~B}$, -HMGN1, and -HMGN2 antibodies. The presence of H2A, H2B, HMGN1, and HMGN2 in the cells before immunoprecipitation was evaluated by including a whole cell lysate control $(\mathrm{wcl})$. 


\section{RESULTS}

\section{Histone deacetylation, rather than acetylation, occurs during a specific temporal window of oligodendrocyte development}

To investigate whether changes in the acetylation of nucleosomal histones occurred during oligodendrocyte lineage progression, we established primary cultures of neonatal rat cortical progenitors and induced them to differentiate by removing the mitogens from the culture medium (Casaccia-Bonnefil et al., 1997). The advantage of such an experimental system is the possibility to follow in vitro the same sequence of events observed during lineage progression in vivo, although within a much shorter time frame (Noble and Murray, 1984; Temple and Raff, 1985; Gard and Pfeiffer, 1993). When cultured in the presence of mitogens, progenitors proliferate and can be identified by a simple bipolar or stellate morphology and positive immunoreactivity for the progenitor markers A2B5 and O4 (Fig. 1A). On mitogen removal, cells exit from the cell cycle within $24 \mathrm{hr}$ and start acquiring secondary and tertiary branches. As progenitors mature, they lose A2B 5 but retain $\mathrm{O} 4$ immunoreactivity. After $48-72 \mathrm{hr}$ of mitogen withdrawal, differentiating oligodendrocytes begin synthesizing
GalC, and, by $96-120 \mathrm{hr}$, they also express the myelin component PLP (Fig. 1A).

To detect changes in histone acetylation during oligodendrocyte lineage progression, protein extracts were harvested from proliferating progenitors cultured in bFGF after 6, 24, and $48 \mathrm{hr}$ of mitogen withdrawal and analyzed by Western blot analysis using an antibody directed against acetyl-lysine residues. Interestingly, two heavily acetylated bands ranging between 10 and 17 $\mathrm{kDa}$ were present in proliferating progenitors (Fig. 1B). As early as $6 \mathrm{hr}$ after mitogen withdrawal, the intensity of the signal for both bands decreased, indicating loss of the acetyl groups from the lysine residues. The decrease of intensity was observed throughout the duration of the experiment, with the weakest acetylation signal observed in cells cultured for $24 \mathrm{hr}$ after mitogen withdrawal (Fig. 1B). Treatment of cells with TSA during this time interval strongly inhibited HDAC activity, as shown by the threefold to fourfold increase of the acetylation signal in TSAtreated samples (Fig. 1B,C).

Although this temporal pattern of deacetylation was observed in four separate experiments, the intensity of the acetylation changes was variable from experiment to experiment. For this
Figure 3. Inhibition of histone deacetylation prevents morphological differentiation of oligo progenitors. $A$, Dose-dependent effect of TSA in preventing morphological changes associated with differentiation. Photomicrograph of progenitors cultured for $1 \mathrm{~d}$ in the absence of TSA or in the presence of $0.1 \mathrm{ng} / \mathrm{ml}(b), 1$ $\mathrm{ng} / \mathrm{ml}(c)$, or $10 \mathrm{ng} / \mathrm{ml}(d)$ TSA. The green immunofluorescence indicates O4-positive cells. The blue immunofluorescence (DAPI) identifies all cell nuclei. Cells treated with increasing doses of TSA display a progressively simpler morphology. $B$, Dose-dependent effect of TSA in inducing changes in acetylation. Western blot analysis of protein lysates obtained from cells treated for $24 \mathrm{hr}$ with $0.1,1$, or $10 \mathrm{ng} / \mathrm{ml} \mathrm{TSA} \mathrm{(+TSA).} \mathrm{After}$ SDS-PAGE, the blots were probed with anti-acetyl lysine antibodies. $C$, Quantitation of the TSA effect on the morphology of cells. Oligodendrocyte progenitors were allowed to differentiate by removal of mitogens from the medium containing $0.1,1$, or $10 \mathrm{ng} / \mathrm{ml}$ TSA for $24 \mathrm{hr}$. After staining live with O4, cells were fixed, processed by immunofluorescence, and then classified in each of the following categories: simple morphology, intermediate morphology, or complex morphology. Cells were classified as simple morphology if they only had short primary branches and bulky processes. Cells were classified as intermediate morphology if they had long primary or secondary branches. Cells were classified as complex morphology if they had tertiary branches. $D$, Effect of sodium butyrate on the morphology of the cells. Oligodendrocyte progenitors were treated with either $0.5 \mathrm{~mm}(a)$ or $5 \mathrm{~mm}(b)$ sodium butyrate. Only concentrations that are known to inhibit histone deacetylase $(b)$ have an effect on progenitors morphology.
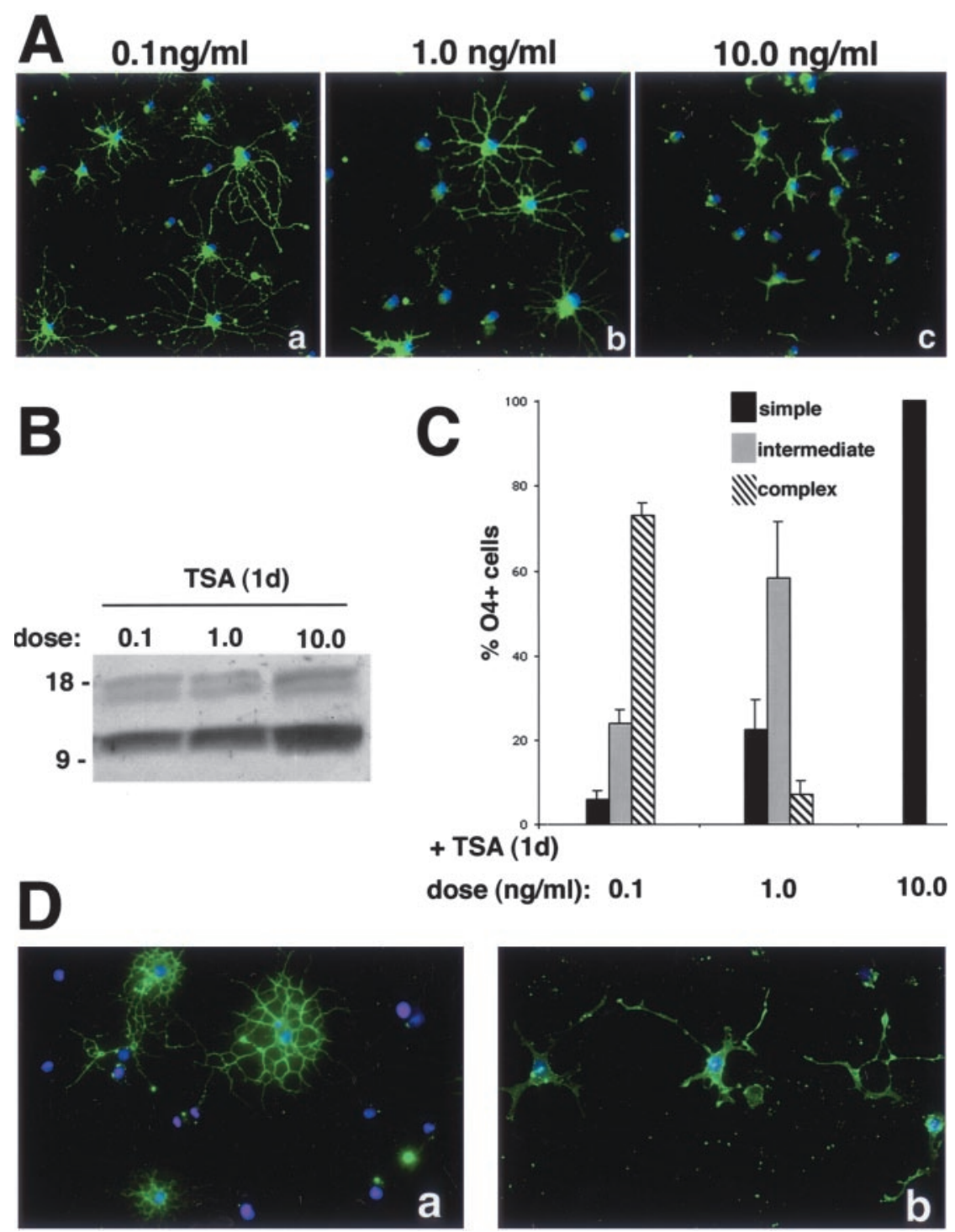
reason, a densitometric analysis of the chemiluminescent signal was performed, and the average values from the separate determinations are shown in Figure $1 C$. Each acetylated band was scanned, and the densitometric value was normalized to the actin content. The level of acetylation in the bFGF sample was arbitrarily defined as $100 \%$. The acetylation signal of the samples harvested at different time points after mitogen removal was then represented as a percentage of the value in the presence of bFGF (Fig. 1C). Interestingly, at $6 \mathrm{hr}$, the average acetylation of $\mathrm{H} 3$ was $53 \%$, and the average of $\mathrm{H} 4$ was $44 \%$ of the values determined in progenitor cells. At $24 \mathrm{hr}$, the average intensity of the acetylation signal decreased even further, reaching $28 \%$ of the original values for $\mathrm{H} 3$ and $13 \%$ for $\mathrm{H} 4$. Finally, at $48 \mathrm{hr}$, the average acetylation signal for $\mathrm{H} 3$ was $36 \%$ and for $\mathrm{H} 4$ was $30 \%$ of the initial levels.

To exclude the possibility that the decreased histone acetylation signal observed during oligodendrocyte lineage progression was attributable to decreased histone levels, cell lysates were harvested at distinct time points and analyzed for protein content by Western blot analysis using antibodies against total histones. As shown in Figure 2, the steady-state protein levels of histones H3, H2A, H2B (Fig. 2A), and histone H4 (Fig. 2B) did not change significantly during the time period examined in this study. We therefore concluded that the decreased histone acetylation signal was not attributable to significant changes in protein levels.

To determine whether the changes in the acetylation during oligodendrocyte differentiation were attributable exclusively to deacetylation of lysine residues in nucleosomal histones (i.e., $\mathrm{H} 2 \mathrm{~A}, \mathrm{H} 2 \mathrm{~B}, \mathrm{H} 3$, and $\mathrm{H} 4$ ) or also affecting other chromatin proteins of the high-mobility group (i.e., HMGNs), we performed immunoprecipitation followed by Western blot analysis. Protein lysates obtained from differentiating oligodendrocyte progenitors were immunoprecipitated with antibodies against acetyl lysine, and the acetylated bands were then identified by Western blot analysis using antibodies recognizing histones $\mathrm{H} 3$ and $\mathrm{H} 4$ (Fig. $2 C$ ), histones $\mathrm{H} 2 \mathrm{~A}$ and $\mathrm{H} 2 \mathrm{~B}$ (Fig. 2D), or the high-mobility group proteins HMGN-1 and HMGN-2 (Fig. 2D). Interestingly, not all of the chromatin proteins were affected by HDAC activity during the onset of oligodendrocyte differentiation. Histone $\mathrm{H} 2 \mathrm{~B}$ and the high-mobility group protein $\mathrm{HMGN}-2$, for instance, although both were detected in cell lysates of oligodendrocyte progenitors, did not show any change in acetylation during oligodendrocyte differentiation (Fig. 2D).

Densitometric analysis of the acetylation signal of $\mathrm{H} 3$ at $24 \mathrm{hr}$ revealed a decrease to $23 \%$ of the values observed in progenitors. A similar decrease in acetylation during the first $24 \mathrm{hr}$ of differentiation was also observed for HMGN-1, in which levels were reduced to $27 \%$ of the initial values. In contrast, the changes of $\mathrm{H} 2 \mathrm{~A}$ were of much smaller entity because, at $24 \mathrm{hr}$, the acetylation signal was still $70 \%$ of the progenitor values. From these data, we conclude that HDAC activity in differentiating oligodendrocytes is primarily directed to lysine residues in the tail of nucleosomal histones $\mathrm{H} 4$ and $\mathrm{H} 3$ and of the high-mobility group protein HMGN-1.

\section{Inhibition of histone deacetylation with TSA prevents branching associated with oligodendrocyte progenitor lineage progression}

To establish the functional significance of histone deacetylation during oligodendrocyte development, differentiation of progenitors was evaluated in the presence of increasing doses of the pharmacological inhibitor of HDAC TSA. Untreated progenitors differentiate very fast in response to mitogen withdrawal, and, within $24 \mathrm{hr}$, cells are characterized by the outgrowth of several fine cellular processes and a complex morphology (Fig. 1A). Treatment of differentiating progenitors with increasing concentrations of TSA progressively inhibited the formation of cellular branches (Fig. $3 A$ ). A quantitative analysis of the effect of the inhibitor on process outgrowth revealed a gradual shift of the prevalent phenotype with increasing doses of TSA. We observed
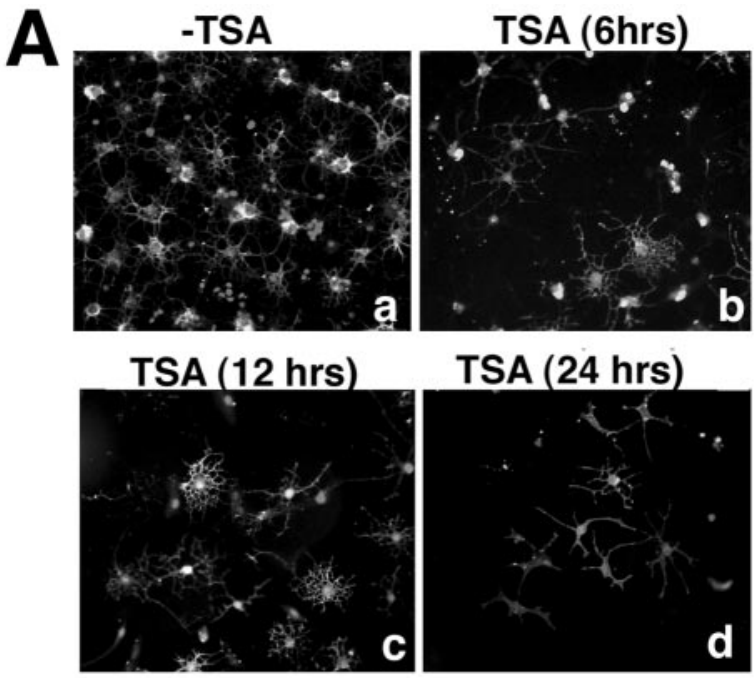

TSA (24 hrs)
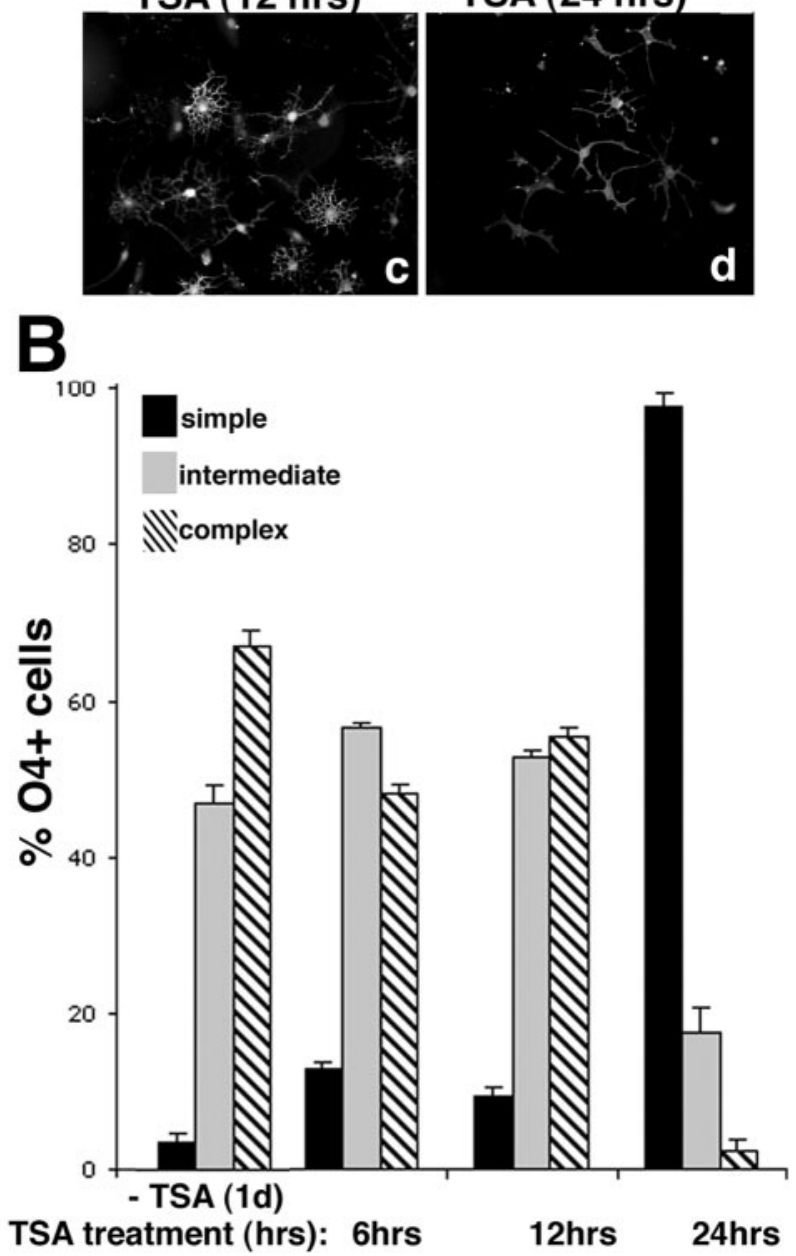

Figure 4. The effect of TSA is time dependent. A, Population analysis of the TSA-dependent effect. Photomicrograph of O4-positive cells cultured for $48 \mathrm{hr}$ in medium without mitogens $(a,-T S A)$ or cultured for $6 \mathrm{hr}(b)$, $12 \mathrm{hr}(c)$, or $24 \mathrm{hr}(d)$ in the presence of $10 \mathrm{ng} / \mathrm{ml} \mathrm{TSA}$, followed by an additional $24 \mathrm{hr}$ of culture in the absence of TSA. Cells were fixed and stained for O4. Stable changes were observed only after $24 \mathrm{hr}$ treatment. $B$, Quantitation of the TSA-dependent effect. O4-positive cells were analyzed under a fluorescence microscope and classified as either simple, intermediate, or complex morphology, as described in Figure $3 C$. The bar graph represents the results of the counts from four to six determinations resulting from two or three experiments each performed in duplicate. 

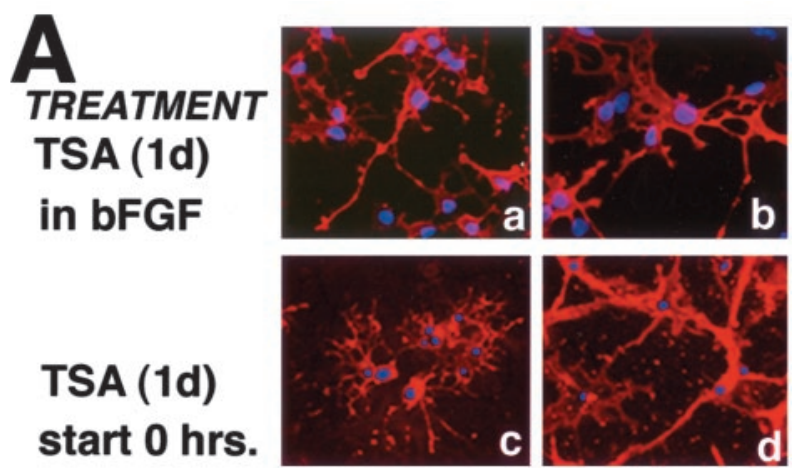

TSA (1d) start 72 hrs.
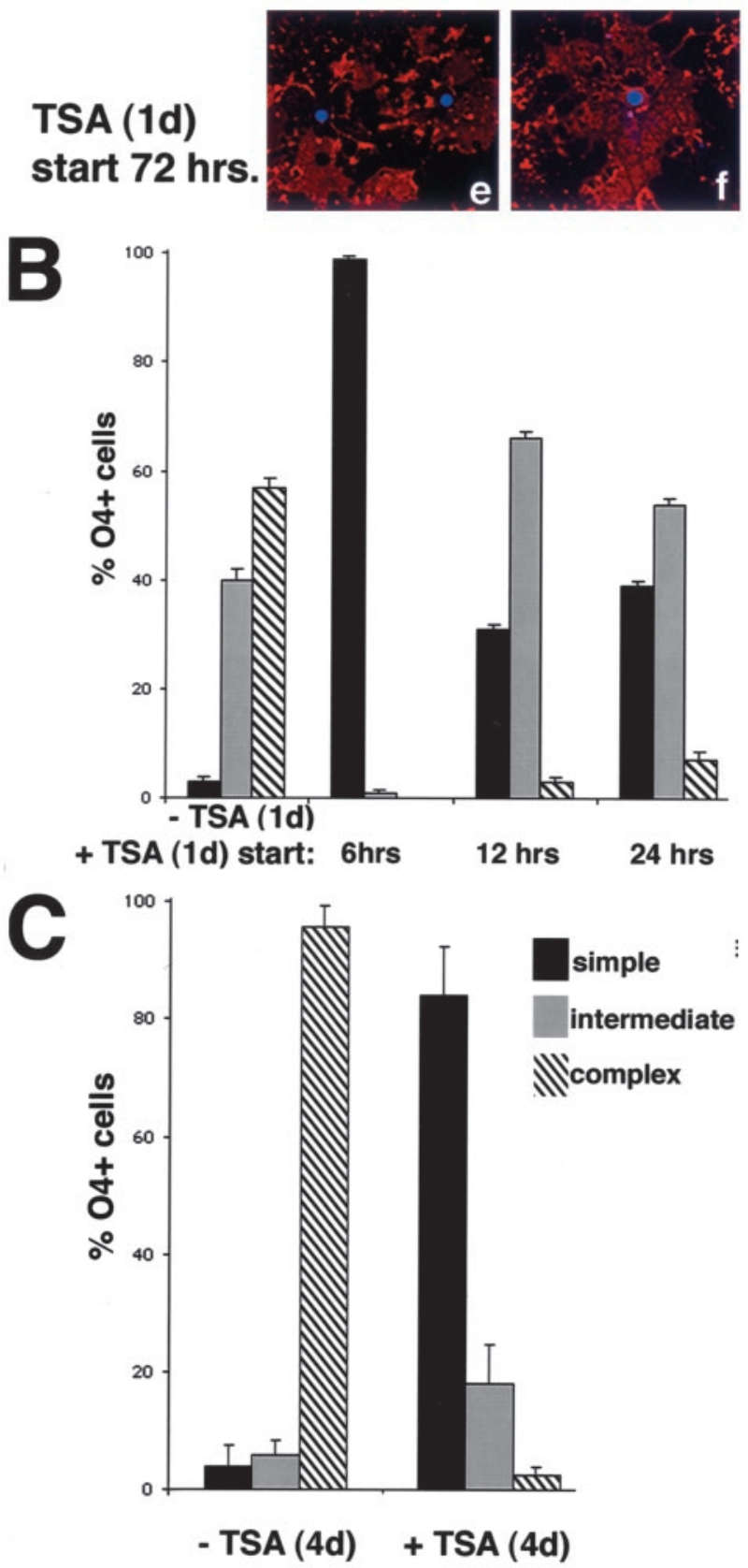

Figure 5. The effect of TSA in preventing morphological differentiation depends on when the treatment started. $A$, Effect of TSA on the morphology. Cells were cultured for $24 \mathrm{hr}$ in the presence of TSA $(b, d, f)$ or in its absence $(a, c, e)$ and then stained for O4 $(a, d)$ and PLP $(e, f)$. TSA treatment did not change the morphology of progenitors cultured in bFGF $(a, b)$. In addition, TSA treatment neither "reverted" the branching a change from the complex morphology of untreated progenitors, to the intermediate phenotype of cells treated with $1 \mathrm{ng} / \mathrm{ml}$ TSA, to the simple morphology of cells treated with $10 \mathrm{ng} / \mathrm{ml} \mathrm{TSA}$ (Fig. $3 C$ ). The progressive effect of increasing concentrations of TSA on morphological differentiation (Fig. $3 A, C$ ) correlated with a detectable increase in the acetylation signal (Fig. $3 B$ ).

The effect of TSA on morphological differentiation of progenitors was observed also with other inhibitors of histone deacetylase, such as sodium butyrate. Lower concentrations of the drug $(0.5 \mathrm{~mm})$ did not affect process outgrowth (Fig. $3 D)$. However, at a concentration known to inhibit HDAC activity (5 mM), sodium butyrate induced morphological changes similar to the ones induced by TSA. Also in this case, the outgrowth of the characteristic fine and complex branches was replaced by the formation of few bulky and thick cytoplasmic processes (Fig. 3D).

To begin to characterize the effect of the HDAC inhibitor on oligodendrocyte branching, we asked what was the minimum duration of the treatment resulting in stable alterations of process outgrowth. For this purpose, cells were induced to differentiate in mitogen-free medium containing $10 \mathrm{ng} / \mathrm{ml}$ TSA for the first 6,12 , or $24 \mathrm{hr}$ of culture and then kept in medium without TSA for an additional $24 \mathrm{hr}$. As shown in Figure 4, the effect of TSA on the morphology of the cells was most evident after $24 \mathrm{hr}$ of treatment. By this time, $>90 \%$ of the cells exhibited a simple morphology. Together, these results suggest that HDAC activity is required for the induction of the morphological changes characteristic of differentiated oligodendrocytes.

\section{TSA treatment is effective in preventing differentiation} only if initiated during a specific temporal window

The time course of histone deacetylation, immediately preceding the onset of oligodendrocyte differentiation, suggested the possible existence of a temporal window of responsiveness of progenitors to differentiative stimuli (Fig. $5 A$ ). This hypothesis predicts that inhibition of histone deacetylation will prevent differentiation only during a specific time frame. To test this hypothesis, we started a $24 \mathrm{hr}$ treatment with TSA at several time points after mitogen withdrawal. Cells were allowed to differentiate in mitogen-free medium for $6,12,24,48$, and $72 \mathrm{hr}$ in the absence of TSA and were then kept for $24 \mathrm{hr}$ in medium containing $10 \mathrm{ng} / \mathrm{ml}$ TSA. At the end of the treatment, cells were fixed, stained with O4, and assessed for morphological differentiation. As predicted by our hypothesis, the effect of TSA in preventing the acquisition of the complex branched morphology was observed only if treatment was started during the first $48 \mathrm{hr}$ of mitogen withdrawal (Fig. 5A,B). However, the earlier start of the treatment correlated with a more prominent effect of TSA on branching. If treatment was initiated at the time of mitogen withdrawal, the cells displayed a very simple morphology after $1 \mathrm{~d}$ (Fig. $5 A, d)$. The simple morphology was retained by the cells even after $4 \mathrm{~d}$ of

of cells cultured for $72 \mathrm{hr}$ in the absence of mitogens $(e, f)$ nor affected the expression of PLP by these cells. B, Quantitation of the effect of $24 \mathrm{hr}$ TSA treatment started at different time points on the morphology of the cells. Oligo progenitors were cultured in medium without mitogens for 6 , 12 , or $24 \mathrm{hr}(-T S A)$ and then treated with TSA for the next $24 \mathrm{hr}(+T S A)$. After staining with the $\mathrm{O} 4$ marker, cells were analyzed by immunofluorescence and classified according to their morphology. Note that the effect of TSA on the morphology of the cells occurs only if the treatment is started early after mitogen withdrawal. $C$, Effect of $4 \mathrm{~d}$ treatment. Treatment of cells with $10 \mathrm{ng} / \mathrm{ml}$ TSA for $4 \mathrm{~d}$ completely prevented branching when it was started immediately after mitogen withdrawal. 

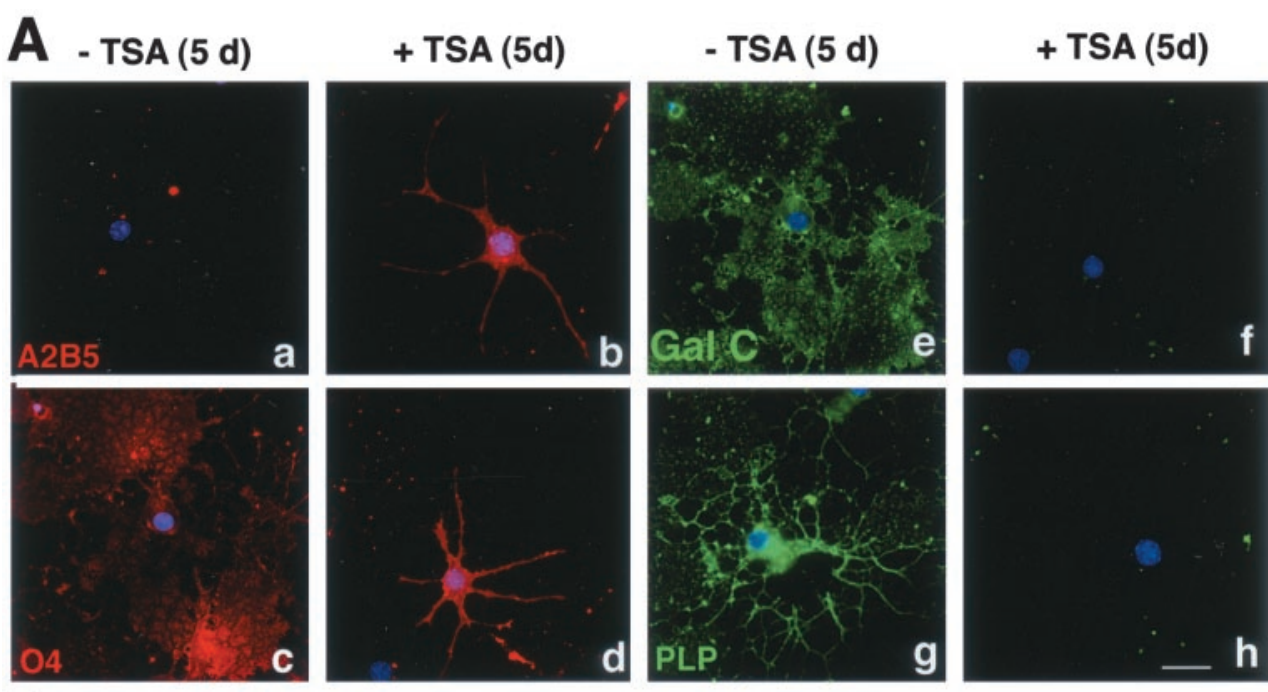

B
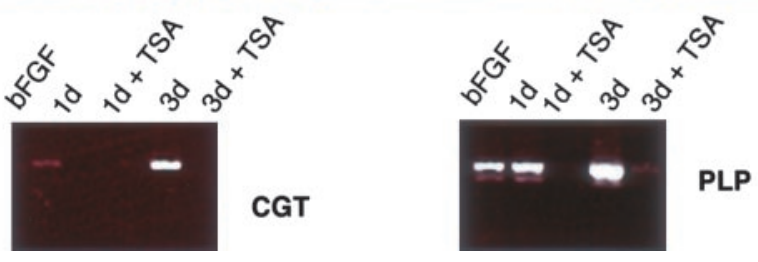
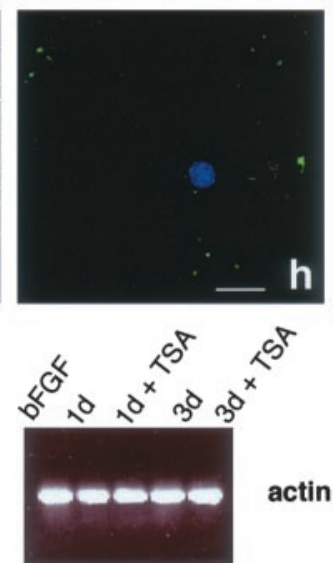

Figure 6. Treatment of oligodendrocyte progenitors with TSA arrests the cells at an immature stage of differentiation. $A$, TSA prevents the expression of late oligodendrocyte differentiation markers. To test the effect of histone deacetylation on the synthesis of lineage-specific markers, progenitors were cultured for $5 \mathrm{~d}$ without mitogens in the absence $(-T S A)$ or presence $(+T S A)$ of TSA. Cells were then processed for immunocytochemistry using antibodies against A2B5 (red, $a, b$ ), $\mathrm{O} 4$ (red, $c, d$ ), GalC ( green, $e, f$ ), and PLP ( green, $g, h$ ). Cell nuclei were visualized using DAPI (blue fluorescence in $a-h$ ). Typically, after $5 \mathrm{~d}$ of mitogen withdrawal, control cells have lost immunoreactivity for the progenitor marker A2B5 $(a)$ but express $\mathrm{O} 4(c), \operatorname{GalC}(e)$, and PLP $(g)$. Preventing histone deacetylation with TSA halters the progression from progenitors to mature oligodendrocytes. TSA-treated cells do not express GalC and PLP $(f, h)$ but express O4 $(d)$ and the progenitor marker A2B5 $(b)$. Scale bar, $20 \mu \mathrm{m}$. $B$, TSA lowers the RNA levels of CGT and PLP. To determine whether the lack of GalC and PLP immunoreactivity in TSA-treated cells was attributable to an effect on the RNA levels, a semiquantitative RT-PCR was performed. Briefly, RNA was isolated from untreated progenitors cultured in bFGF ( $b F G F)$ or differentiated in mitogen-free medium for $1 \mathrm{~d}$ ( $1 d$ ) or $3 \mathrm{~d}$ $(3 d)$. For TSA-treated cultures, the inhibitor was kept in the medium for $1 \mathrm{~d}(1 d+T S A)$ or $3 \mathrm{~d}(3 d+T S A)$ after mitogen withdrawal. After conversion into cDNA, the same amount was amplified using primers specific for actin, CGT, and PLP.

treatment (Fig. 5C). Similar results were obtained when the treatment was started $6 \mathrm{hr}$ after the removal of mitogens (Fig. $5 B)$. However, when TSA was added to the medium after the cells had began to emit long primary branches (i.e., after 12 or $24 \mathrm{hr}$ of culture in mitogen-free medium), the cells did not revert to a simpler morphology and did not elaborate additional processes. Therefore, they were characterized as "intermediate phenotype" (Fig. 5B). Finally, the start of treatment after differentiation had occurred (i.e., after 72 or $96 \mathrm{hr}$ of culture in mitogen-free medium) did not revert the cells to a simpler phenotype. In this case, TSA-treated cells displayed the typical branching and membrane sheets (Fig. $5 A, f$ ) characteristic of mature oligodendrocyte (Fig. $5 A, e)$. From these results, we conclude that TSA is not effective after the differentiation program has been initiated but prevents the progression to a mature phenotype if deacetylation is inhibited during the first 24-48 hr after mitogen withdrawal.

\section{Inhibition of histone deacetylation with TSA prevents the synthesis of oligodendrocyte differentiation markers}

The effect of TSA treatment on morphological branching suggested that inhibiting histone deacetylation prevented the acquisition of a differentiated phenotype, although it did not address whether the expression of specific differentiation genes was also inhibited. To test the role of HDAC activity in oligodendrocyte differentiation, we therefore characterized the expression profile of stage-specific markers in the absence and presence of TSA. Untreated oligodendrocyte progenitors cultured in bFGF are characterized by the presence of the surface antigen A2B5 and the lipid sulfatide O4 (Bansal et al., 1989). When these cells are induced to differentiate by mitogen withdrawal, they lose A2B5 immunoreactivity and begin to express myelin components. $\mathrm{GalC}$, the major lipid in myelin, is typically expressed between 48 and $72 \mathrm{hr}$, whereas PLP is expressed after 96-120 hr. TSAtreated cells, in contrast, did not lose A2B5 immunoreactivity and did not express the myelin components GalC and PLP, even 120 hr after mitogen withdrawal (Fig. $6 A$ ). Loss of PLP immunoreactivity occurred in the vast majority of the TSA-treated cells (Fig. 7). To determine whether decreased PLP immunoreactivity was attributable to decreased RNA levels, we used an RT-PCR. Consistent with an effect of TSA in modulating gene expression by affecting histone acetylation, decreased levels of PLP and GalC in the TSA-treated cells correlated with decreased RNA levels (Fig. 6B) for PLP and CGT (i.e., the synthetic enzyme responsible for the production of GalC). These data suggest that presumptive chromatin changes attributable to histone deacetylation are necessary for the expression of oligodendrocyte differentiation markers.

\section{The effect of histone deacetylation inhibition on oligodendrocyte differentiation is independent of cell cycle exit}

The inhibitory effect of TSA on oligodendrocyte lineage progression could have been attributable to a direct effect of histone deacetylation on the differentiation program itself or to an indirect effect on proliferation. To distinguish between these two possibilities, we labeled cells in $\mathrm{S}$ phase with the thymidine analog BrdU and then counted the number of BrdU-positive cells in TSA-treated and untreated cultures. Briefly, progenitors were cultured in the presence of bFGF or in the absence of mitogen for $6,12,24$, and $48 \mathrm{hr}$. All cultures were labeled with $10 \mu \mathrm{M} \mathrm{BrdU}$ during the last $6 \mathrm{hr}$ before the end of the experiment. Cells were then fixed and double stained with antibodies against BrdU and against specific progenitor markers (i.e., A2B5 and O4). The number of $\mathrm{A} 2 \mathrm{~B} 5^{+} / \mathrm{BrdU}^{+}$cells and ${ }^{+} / \mathrm{BrdU}^{+}$cells (Fig. $8 \mathrm{~A}$ ) was counted, and the percentage of BrdU-incorporating cells was 

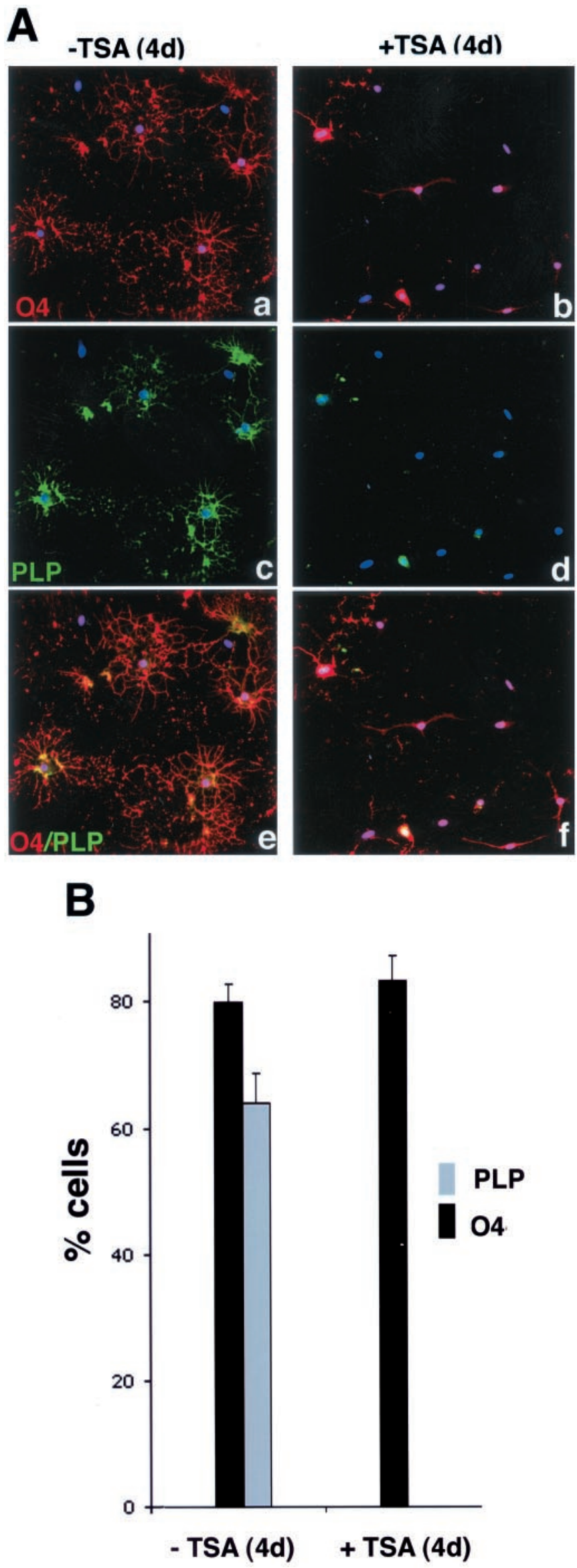

calculated by dividing the number of double-labeled cells by the total number of $\mathrm{A} 2 \mathrm{~B} 5{ }^{+}$and $\mathrm{O} 4{ }^{+}$cells (Fig. $8 \mathrm{~B}$ ). The percentage of cells in $\mathrm{S}$ phase was similar in TSA-treated and untreated progenitors cultured in bFGF (Fig. $8 A, B$ ). A similar percentage of proliferating cells was also observed in TSA-treated and untreated cells after 6 and $12 \mathrm{hr}$ of mitogen withdrawal. Interestingly, TSA-treated cells showed a faster kinetic of withdrawal from the cell cycle, because $100 \%$ of the treated cells exited the cell cycle at $24 \mathrm{hr}$, whereas $30 \%$ of the untreated cells was still proliferating (Fig. $8 B$ ). This effect was likely attributable to increased levels of the cell cycle inhibitor p21waf-1 (Fig. 8C) in TSA-treated cells, which is consistent with reports in other cell types (Yoshida et al., 1995; Sowa et al., 1999; Xiao et al., 1999). From these results, we conclude that the inability of oligodendrocyte progenitors to differentiate in the presence of HDAC inhibitors was not attributable to increased proliferation.

\section{Removal of histone deacetylase inhibition allows recovery of morphological branching but not the synthesis of late differentiation markers}

The acetylation state of nucleosomal histones is a reversible event because acetyl groups are transferred to lysine residues by the activity of acetyltransferases and removed by the activity of histone deacetylases. TSA inhibits the removal of acetyl groups from the histone tails, and, presumably, the activity of HDAC is restored immediately after removal of the drug, unless histone modifications have induced more permanent changes in chromatin conformation. To test the reversibility of TSA effect, progenitors were treated during the first $24 \mathrm{hr}$ of mitogen withdrawal and then the drug was washed away, and the cells were kept in mitogen-free medium for a total of 3 or $5 \mathrm{~d}$. After this recovery time, cells were fixed, stained, and then analyzed for branched morphology and myelin gene expression (Fig. 9). Three days after mitogen withdrawal, untreated cells were highly branched and expressed both lipid sulfatides (identified by $\mathrm{O} 4$ immunoreactivity) and galactocerebrosides (identified by GalC immunoreactivity). At the same time point, cells that were treated with TSA during the first $24 \mathrm{hr}$ showed shorter cellular processes and barely detectable levels of GalC. Five days after mitogen withdrawal, untreated cells expressed high levels of PLP and had developed extensive myelin sheets (Fig. 9A). At the same time point, however, cells that were treated with TSA for the first $24 \mathrm{hr}$ did not elaborate complex membranes and expressed very low levels of PLP (Fig. 9A). Interestingly, a Western bot analysis of cell extracts obtained from cells at distinct recovery times reveals fast deacetylation kinetics after the removal of the drug (Fig. 9B). These data suggested that the effects of preventing histone

\footnotetext{
Figure 7. Inhibition of histone deacetylase activity prevents the progression of $\mathrm{O}^{+}$cells to a mature phenotype. $A$, TSA treatment prevents branching and PLP expression. Oligodendrocyte progenitors were allowed to differentiate by removing the mitogens from the culture medium in the absence $(a, c, e)$ or presence $(b, d, f)$ of $10 \mathrm{ng} / \mathrm{ml} \mathrm{TSA}$. The medium was replaced every other day, and, after $4 \mathrm{~d}$, cells were stained with antibodies against $\mathrm{O} 4$ (red immunofluorescence in $a, b$ and $e, f$ ) and PLP (green immunofluorescence in $c, d$ and $e, f$ ). DAPI (blue immunofluorescence) was used to identify cell nuclei. $B$, TSA treatment reduces the proportion of cells expressing PLP. After immunohistochemistry, treated and untreated cells were examined under a fluorescence microscope, and three fields were counted from three distinct experiments, each performed in duplicate. The bar graphs represent the results of the quantitation.
} 
A

- TSA
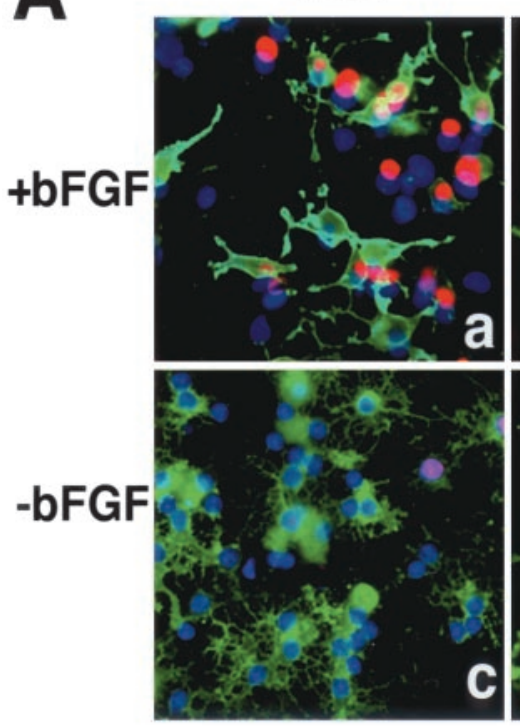

c
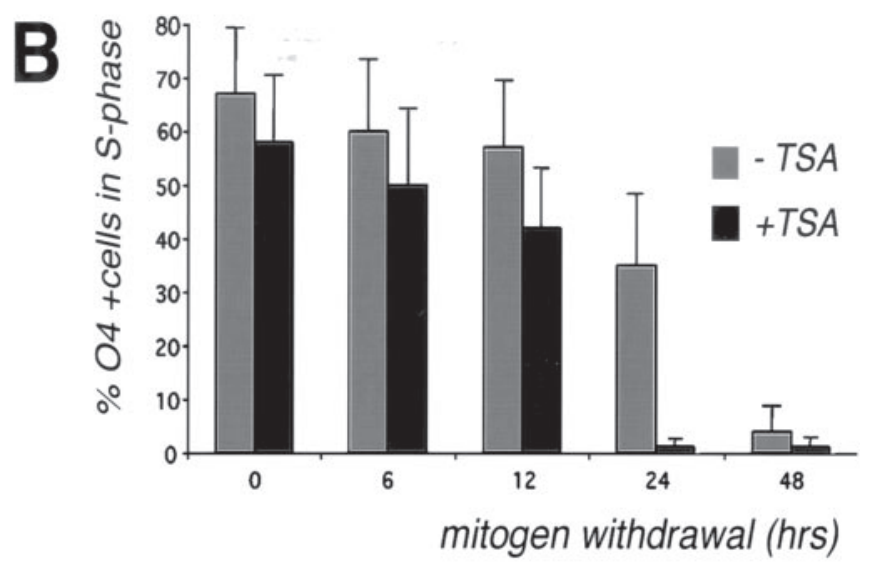
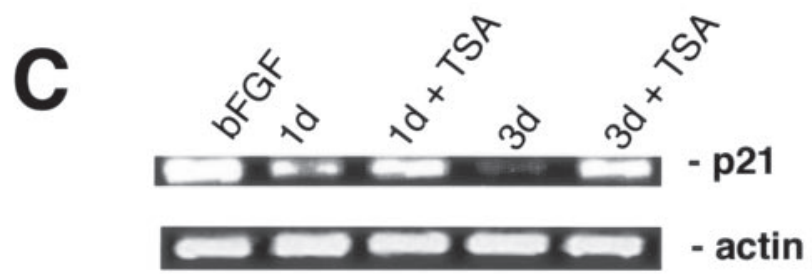

Figure 8. Inhibition of histone deacetylation blocks differentiation but not cell cycle exit. $A$, BrdU incorporation in TSA-treated cultures. Progenitors were kept proliferating in the presence of bFGF $(a, b)$ or were allowed to differentiate by removing the mitogen from the medium $(c, d)$ in the presence $(b, d)$ or absence $(a, c)$ of $10 \mathrm{ng} / \mathrm{ml}$ TSA. Cells in S phase were pulse labeled for $6 \mathrm{hr}$ with $10 \mu \mathrm{M} \mathrm{BrdU}$ at $6,12,24$, and $48 \mathrm{hr}$ and then identified by positive immunoreactivity for $\mathrm{BrdU}($ red $)$ and $\mathrm{O}^{+}$ (green) to identify proliferating cells. DAPI (blue) was used to identify all the cell nuclei. Scale bar, $20 \mu \mathrm{m}$. $B$, TSA treatment does not increase the number of cells in $\mathrm{S}$ phase. The number of double-labeled $\mathrm{O}^{+} / \mathrm{BrdU}^{+}$ cells was counted and expressed as a percentage of the total number of $\mathrm{O}^{+}{ }^{+}$cells. The gray bars represent the number of proliferating cells in the untreated cultures, whereas the black bars represent the number of proliferating cells in the TSA-treated cultures. $C$, The RNA levels of the cell cycle inhibitor p21 are increased by TSA. RNA was isolated from progenitors cultured in the absence or presence of $10 \mathrm{ng} / \mathrm{ml}$ TSA. Amplification of the mRNA was performed by semiquantitative RT-PCR. Actin levels were measured as internal control. deacetylation during the first $24 \mathrm{hr}$ of mitogen withdrawal are only partially reversible.

\section{TSA blocks the progression of progenitors into oligodendrocytes but not into astrocytes}

Cortical oligodendrocyte progenitors have the ability to differentiate in vitro into oligodendrocytes, when cultured in the absence of mitogens, or into type II astrocytes, when cultured in the presence of serum. The results described above show that histone deacetylation was necessary for oligodendrocyte differentiation. We now asked whether histone deacetylation was crucial also for the progression into type II astrocytes. Progenitors were cultured in serum containing medium with or without TSA for 7-10 $\mathrm{d}$ and then stained for GFAP (Fig. 10). In the presence of bFGF or after the removal of mitogens, progenitors do not express GFAP (data not shown). However, after 7-10 d of culture in medium containing $20 \%$ serum, cells can be identified as "protoplasmic" astrocyte or type II astrocytes, characterized by a stellate morphology with thick cytoplasmic processes and GFAP expression. Interestingly, the presence of TSA in the medium did not affect the morphology or the expression of astrocyte markers and were virtually indistinguishable from untreated controls (Fig. 10). We conclude that histone deacetylation is a specific event occurring during differentiation of bipotential progenitors into the oligodendrocyte but not into the astrocyte lineage.

\section{DISCUSSION}

Histone deacetylation is necessary for oligodendrocyte differentiation

The mechanisms responsible for oligodendrocyte differentiation are still primarily not understood. Recent progress has been made in the identification of transcription factors regulating the specification of oligodendrocyte progenitors from multipotential neural stem cells, but the steps involved in the subsequent progression to a myelinating cell are still primarily not understood. Several lines of evidence have established the existence of an obligate relationship between cell cycle exit and differentiation. Although differences might exist between progenitors isolated from the optic nerve or from the cerebellar or cortical cortex (Ghiani and Gallo, 2001), it can be stated that the presence of mitogens favors cell division at the expenses of differentiation, whereas the absence of mitogens favors withdrawal from the cell cycle and oligodendrocyte differentiation (Noble and Murray, 1984; Temple and Raff, 1985). In addition, clonal analysis of single optic rat nerve progenitors indicated that, in the presence of specific extracellular signals, cells divide a certain number of times before they stop and differentiate (Temple and Raff, 1986; Barres et al., 1994). Finally, phenotypic analysis of mice with targeted deletions for genes encoding the cell cycle inhibitors p21-Waf1 or p27-Kip1 indicated that differentiation of oligodendrocyte progenitors was clearly impaired (Casaccia-Bonnefil et al., 1997, 1999; Zezula et al., 2001). These results led to the hypothesis that cell cycle inhibitors may be sufficient to induce differentiation of oligodendrocyte progenitors. However, when p27-Kip1 levels were increased in proliferating oligodendrocyte progenitors by treatment with neurotransmitters (Ghiani et al., 1999) or by viral gene transfer (Tikoo et al., 1998; Tang et al., 1999), the cells stopped proliferating but did not differentiate. Together, these data indicated that, besides cell cycle regulators, other elements might be required to start the oligodendrocyte transcriptional program of differentiation.

Studies in other lineages indicated that chromatin modifiers 


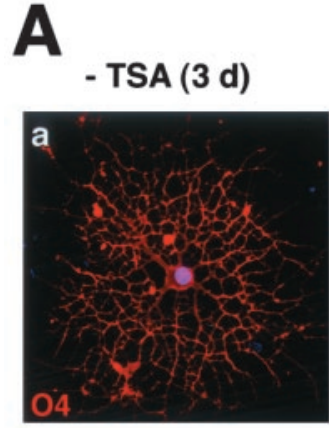

Figure 9. The effect of TSA treatment on morphological differentiation of progenitors is reversible. $A$, Recovery after TSA washout. Oligodendrocyte progenitors were allowed to differentiate in the absence of TSA by withdrawal of mitogen from the medium for either $3 \mathrm{~d}(a, e, i)$ or $5 \mathrm{~d}(c, g, k)$. The TSA-treated group was exposed to $10 \mathrm{ng} / \mathrm{ml}$ TSA during the first $24 \mathrm{hr}$ of mitogen withdrawal and then allowed to recover for an additional $2 \mathrm{~d}$ $(b, f, j)$ or $4 \mathrm{~d}(d, h, l)$ in the absence of the drug. Cells cultured for $3 \mathrm{~d}(a-j)$ were and GalC (green), whereas the nuclei were identified using DAPI (blue). Cells cultured for $5 \mathrm{~d}$ were stained with antibodies against $\mathrm{O} 4$ (red) and PLP (green). Note that the alterations of the cell morphology induced by TSA were completely reversible, whereas the expression of myelin-specific genes was weaker in cells treated with TSA during the first $24 \mathrm{hr}$ of Recovery of deacetylation after TSA washout. Western blot analysis of protein lysates obtained from cells treated for $1 \mathrm{~d}$ with $10 \mathrm{ng} / \mathrm{ml}$ TSA $(0)$ and from cells allowed to recover in the absence of TSA for $1 \mathrm{~d}(1 d), 2 \mathrm{~d}(2 d)$, or $3 \mathrm{~d}(3 d)$. Note that, after removal of the HDAC inhibitor from the medium, deacetylation occurs quite rapidly, and this correlates with the recovery of branching.
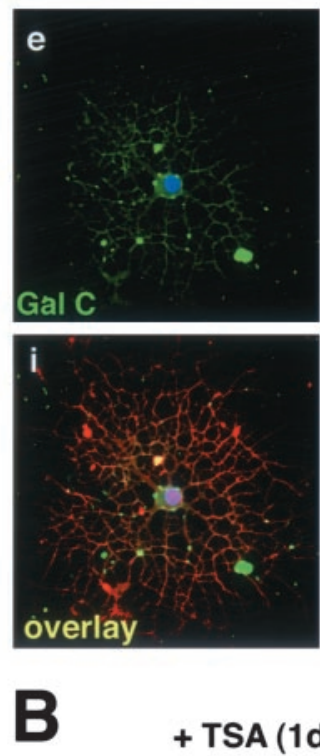
stained with antibodies against $\mathrm{O} 4$ (red) mitogen withdrawal. Scale bar, $20 \mu \mathrm{m} . B$,
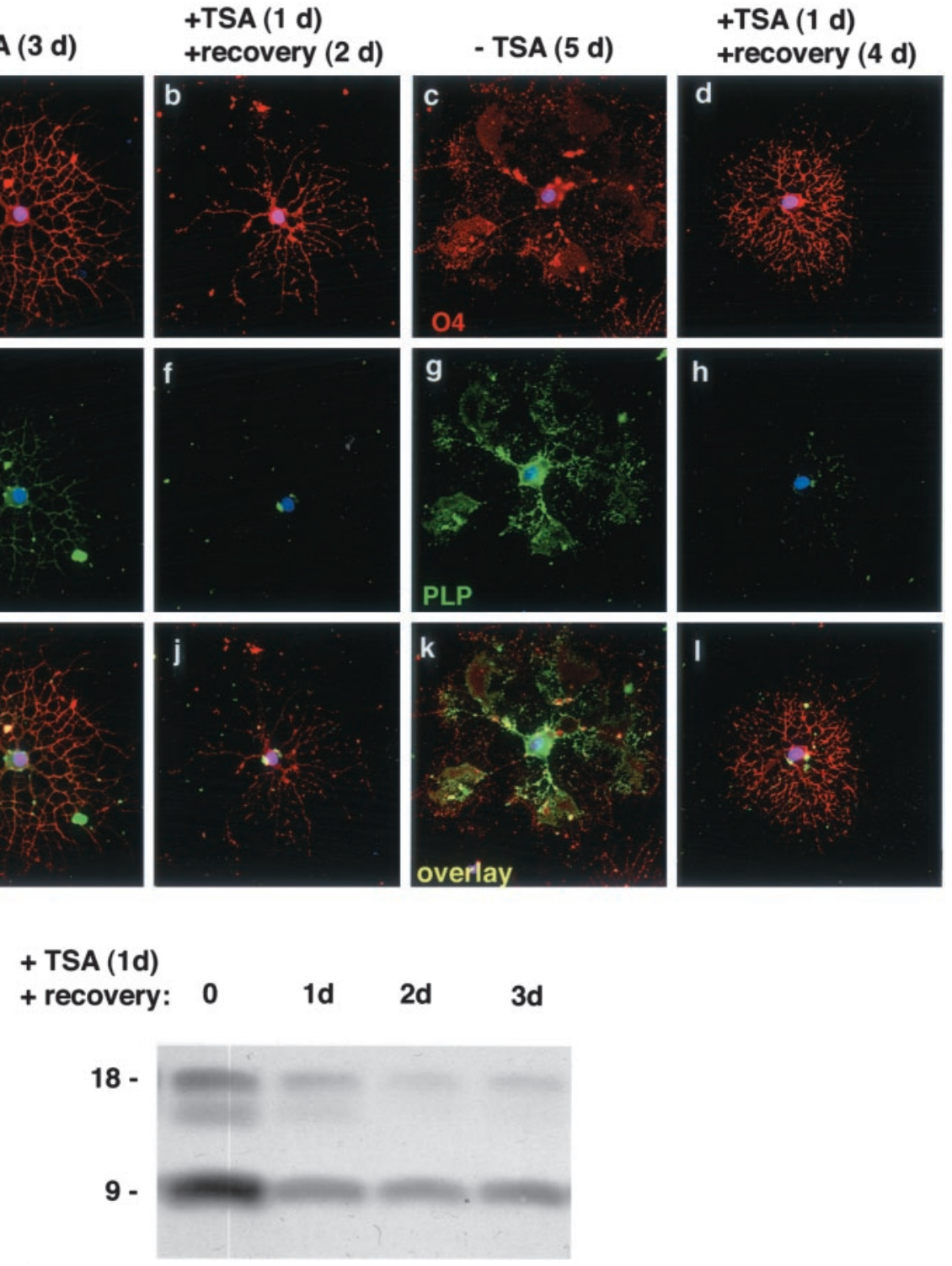

with histone acetyltransferase activity are necessary for the induction of terminal differentiation. The recruitment of coactivators such as p300 in a complex with other transcription factors is able to activate expression of neuronal and astrocytic genes.

Based on these studies, we asked whether histone acetylation could be a molecular mechanism that, together with molecules regulating cell cycle exit, modulates the access of transcription factors to the promoter regions of genes involved in oligodendrocyte differentiation. To test this hypothesis, we induced cell cycle exit by removing the mitogens from the culture medium. There are several advantages in using mitogen withdrawal as an experimental paradigm of oligodendrocyte differentiation. First, it allows the study of events "intrinsic" to the cell, in the absence of additional signals from the extracellular environment. Second, differentiation of progenitors proceeds in a sequence of temporally well defined stages, each characterized by specific morphological features and unique antigenic repertoire (Pfeiffer et al., 1993). Using this model system, we first showed that histone deacetylation, rather than acetylation, occurs in primary cortical oligodendrocyte progenitors during the temporal window preced- ing the onset of differentiation. We then addressed the necessity of this event for oligodendrocyte differentiation by testing the consequences of histone deacetylase inhibitors on oligodendrocyte lineage progression. Because the acetyl groups on nucleosomal histone tails are in a dynamic equilibrium based on the activity of HATs and deacetylases (e.g., HDACs), blockers of HDAC, such as TSA and sodium butyrate, increase the histone acetylation state (Fig. 3). Our data indicate that TSA prevented the progression of progenitors to mature oligodendrocytes (Figs. 3-7). Although we cannot formally exclude the possibility that TSA may act also on proteins other than nucleosomal histones, our data using antibodies directed against acetylated lysine residues detected changes only in proteins with a molecular weight between 9 and $18 \mathrm{kDa}$. These bands were further characterized by their immunoreactivity with antibodies against the nucleosomal histones $\mathrm{H} 2 \mathrm{~A}, \mathrm{H} 3$, and $\mathrm{H} 4$ and the high-mobility group protein $\mathrm{HMGN}-1$. In addition, several studies in other cell types have indicated the specificity of TSA on the inhibition of HDAC activity at the concentrations used in our studies (Yoshida et al., 1990, 1995). Finally, additional data on the specificity of TSA as 

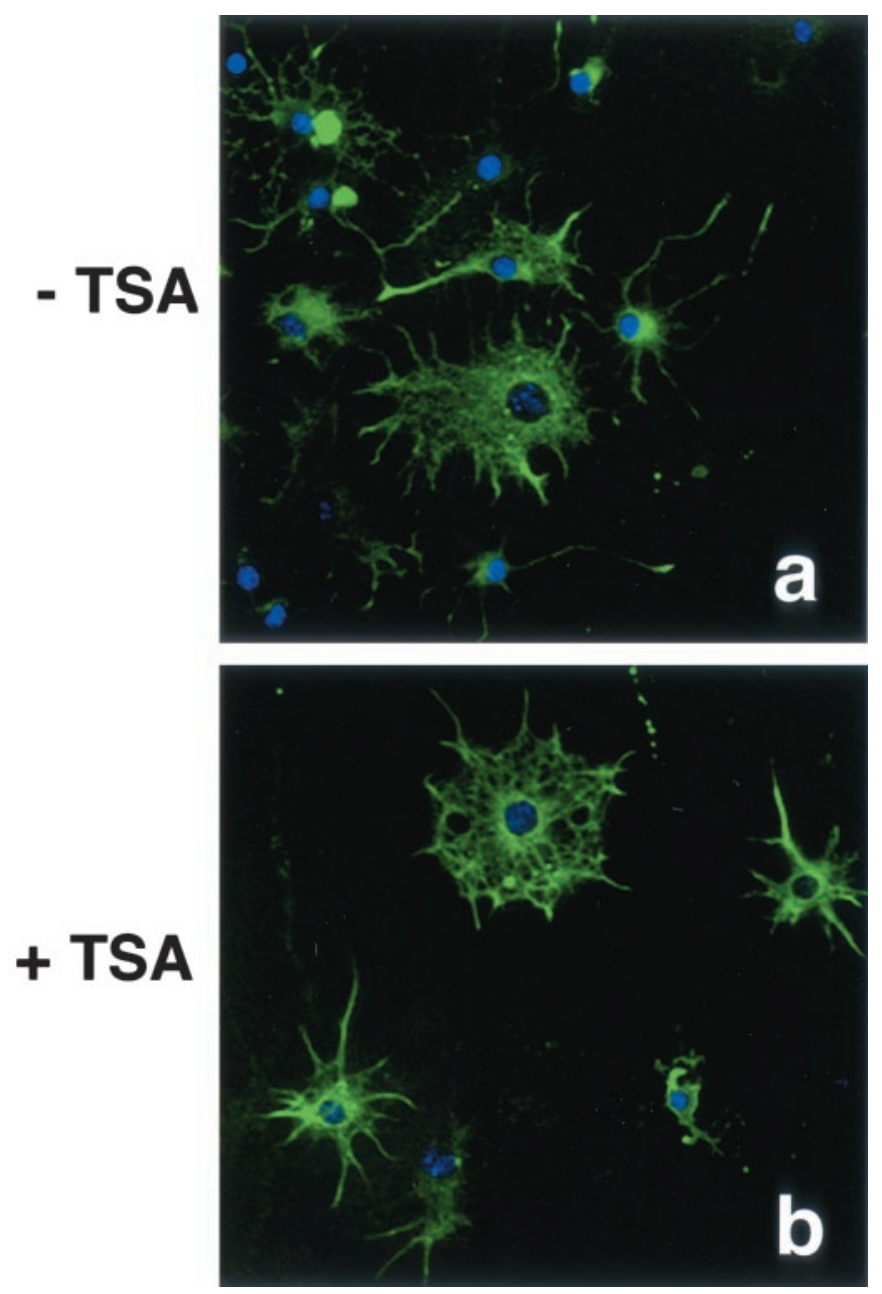

Figure 10. Inhibition of histone deacetylase activity does not prevent differentiation of cortical progenitors into type IIA astrocytes. Rat cortical progenitors were differentiated into type II astrocytes cultured in medium supplemented with $20 \%$ FCS in the absence $(a)$ or presence $(b)$ of TSA and then stained for glial fibrillary acidic protein (green fluorescence). No difference was observed in either morphology or GFAP expression between treated and untreated cells.

inhibitor of HDAC have been provided by the recent crystal structure of the histone deacetylase catalytic core bound to TSA (Finnin et al., 1999). Together, these evidences validate the use of TSA as a specific inhibitor of HDAC enzymatic activity.

\section{Bulk histone deacetylation is transiently observed during oligodendrocyte differentiation}

Although histone acetylation-deacetylation has been shown to regulate the activity of specific promoter regions, this is the first study to our knowledge of bulk histone deacetylation associated

Figure 11. A proposed model of the role of histone deacetylation in oligodendrocyte differentiation. $A$, Direct model. The first model assumes that histone deacetylation occurs directly in the promoter of specific differentiation genes (e.g., myelin genes). In the presence of mitogens, nucleosomal histones are acetylated on lysine residues (orange circles with $\mathrm{COO}-$ tails), and this results in open chromatin conformation and exposure of negative regulatory sites (green rectangles) in the promoter region of myelin genes. Binding of specific regulatory molecules (black ovals) to these sites is favored, and progenitors are kept in an undifferentiated state. On recruitment of HDAC, induced by the withdrawal of
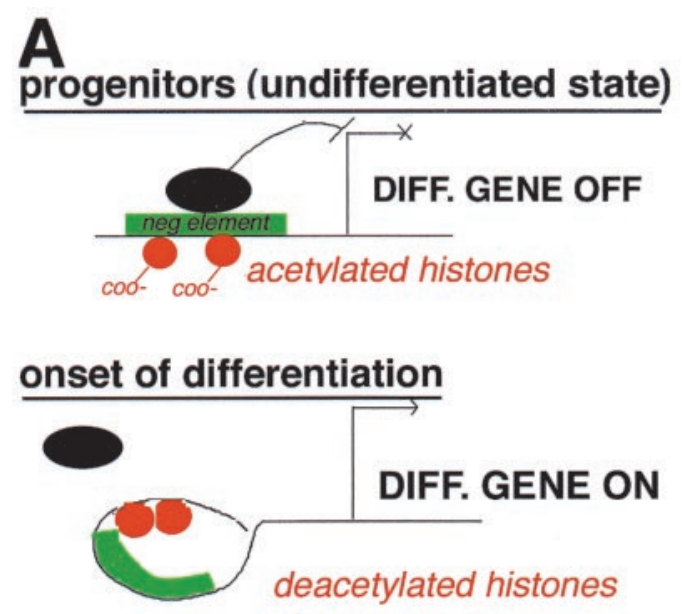

B

progenitors (undifferentiated state)

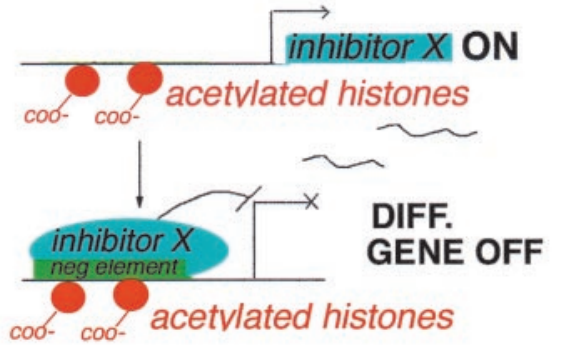

\section{onset of differentiation}

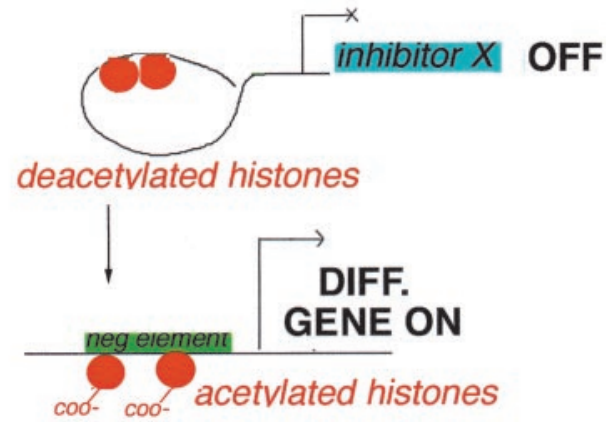

$\overline{\text { mitogens, histone tails are deacetylated (orange circles with no tails), and }}$ the chromatin around the negative regulatory sites is compacted, thus preventing the access to transcriptional inhibitors. This event results in onset of differentiation caused by compaction of negative cis-element on the promoter region of myelin genes. $B$, Indirect model. The second model predicts that histone deacetylation occurs on the promoter of genes encoding for differentiation inhibitors (e.g., gene X). In progenitor cells, nucleosomal histones in the promoter region of the differentiation inhibitor are acetylated (orange circles with $\mathrm{COO}-$ tails), resulting in open chromatin conformation and expression of the inhibitor $\mathrm{X}$. This in turn may bind to negative regulatory sites on differentiation genes and prevent their expression. Onset of differentiation in this case is initiated by recruitment of $\mathrm{HDAC}$ to the promoter region, resulting in chromatin compaction and decreased expression of the differentiation inhibitor. According to this model, the negative element on the promoter of differentiation genes may be acetylated but inactive, because of the absence of gene $\mathrm{X}$ (left), or deacetylated and compacted (right). In both cases, the expression of differentiation genes is activated by histone deacetylation. 
with differentiation of progenitor cells. Because deacetylation of nucleosomal histones is associated with repressed chromatin structure, the detection of this event during a specific temporal window after mitogen withdrawal and before onset of differentiation raises several questions. Does repression occur during oligodendrocyte lineage progression? If so, what is the extent of transcriptional repression event? The importance of transcriptional repression in oligodendrocyte lineage progression is supported by numerous studies describing progressive loss of specific gene products during normal oligodendrocyte development. There is general consensus regarding downregulation of specific surface antigens (Raff et al., 1984), transcription factors (Wegner, 2001), differentiation inhibitors (Kondo and Raff, 2000), growth factor receptors (Hart et al., 1989; Ellison and de Vellis, 1994; Bansal et al., 1996; Rodriguez-Pena, 1999), guidance molecules, and cell cycle genes (Casaccia-Bonnefil et al., 1997; Huang et al., 2002) during oligodendrocyte differentiation. In vivo, this decrease in gene expression occurs gradually, whereas in vitro, the withdrawal of mitogens accelerates timing of differentiation, therefore "condensing" changes in gene expression within a much shorter timeframe. This "synchronized" repression of multiple genes could explain the "bulk" histone deacetylation observed in our study.

\section{A proposed model of the role of histone deacetylation in oligodendrocyte differentiation}

Our observations suggest that histone deacetylation is required for differentiation of oligodendrocyte progenitors. Because histone deacetylation is associated with chromatin compaction, we propose two models to explain the role possibly played by chromatin remodeling in oligodendrocyte differentiation. According to one model, compaction of chromatin may occur on negative regulatory sites of differentiation genes (Fig. 11A). According to this model, the promoter activity of specific differentiation genes, such as PLP, is maintained low in progenitor cells (Timsit et al., 1995; Dickinson et al., 1996; Mallon et al., 2002) by the interaction of specific repressors binding negative regulatory sites in the promoter region (Berndt et al., 1992; Wight et al., 1997). Histone deacetylation in these regions would result in chromatin compaction and difficult access of repressors to these negative regulatory elements. This change of conformation therefore reduces repression and results in increased levels of expression in the gene product (Fig. 11A). According to an alternative model, chromatin compaction may occur in the promoter region of genes encoding for inhibitors of differentiation site (i.e., Ids) (Kondo and Raff, 2000), thereby blocking the access of the transcriptional apparatus to the START site. In this case, chromatin compaction may be responsible for the decreased levels of molecules known to sequester activators of myelin gene expression, such as the Ids (Fig. $11 B$ ). These models are not mutually exclusive and may well both occur within the same cell at a given time.

\section{Concluding remarks}

In conclusion, we identified histone deacetylase activity as necessary for oligodendrocyte differentiation. This mechanism involves deacetylation of chromatin components and is followed by presumptive chromatin remodeling. Blocking deacetylation prevents differentiation and suggests that transcriptional repression is a crucial event during oligodendrocyte lineage progression. A better understanding of these molecular events will allow the design of therapies targeted at efficient remyelination.

\section{REFERENCES}

Ashraf SI, Ip YT (1998) Transcriptional control: repression by local chromatin modification. Curr Biol 8:R683-R686.

Ballas N, Battaglioli E, Atouf F, Andres ME, Chenoweth J, Anderson ME, Burger C, Moniwa M, Davie JR, Bowers WJ, Federoff HJ, Rose DW, Rosenfeld MG, Brehm P, Mandel G (2001) Regulation of neuronal traits by a novel transcriptional complex. Neuron 31:353-365.

Bansal R, Pfeiffer SE (1997) FGF-2 converts mature oligodendrocytes to a novel phenotype. J Neurosci Res 50:215-228.

Bansal R, Warrington AE, Gard AL, Ranscht B, Pfeiffer SE (1989) Multiple and novel specificities of monoclonal antibodies O1, O4, and $\mathrm{R}-\mathrm{mAb}$ used in the analysis of oligodendrocyte development. J Neurosci Res 24:548-557.

Bansal R, Kumar M, Murray K, Morrison R, Pfeiffer SE (1996) Regulation of FGF receptors in the oligodendrocyte lineage. Mol Cell Neurosci 7:263-275.

Barres BA, Lazar MA, Raff MC (1994) A novel role for thyroid hormone, glucocorticoids and retinoic acid in timing oligodendrocyte development. Development 120:1097-1108.

Berndt JA, Kim JG, Hudson LD (1992) Identification of cis-regulatory elements in the myelin proteolipid protein (PLP) gene. J Biol Chem 267:14730-14737.

Casaccia-Bonnefil P, Carter B, Dobrowsky R, Chao MVC (1996) Death of oligodendrocytes mediated by the interaction of nerve growth factor with its receptor p75. Nature 383:716-719.

Casaccia-Bonnefil P, Kiyokawa H, Tikoo R, Friedrich V, Koff A, Chao MVC (1997) Oligodendrocyte precursor differentiation is perturbed in the absence of the cyclin-dependent Kinase inhibitor p27Kip1. Genes Dev 11:2335-2346.

Casaccia-Bonnefil P, Hardy RJ, Teng KK, Levine JM, Koff A, Chao MV (1999) Loss of p27kip1 function results in increased proliferative capacity of oligodendrocyte progenitors but unaltered timing of differentiation. Development 126:4027-4037.

Chong JA, Tapia-Ramirez J, Kim S, Toledo-Aral JJ, Zheng Y, Boutros MC, Altshuller YM, Frohman MA, Kraner SD, Mandel G (1995) REST: a mammalian silencer protein that restricts sodium channel gene expression to neurons. Cell 80:949-957.

Csordas A (1990) On the biological role of histone acetylation. Biochem J 265:23-38.

Dickinson PJ, Fanarraga ML, Griffiths IR, Barrie JM, Kyriakides E, Montague P (1996) Oligodendrocyte progenitors in the embryonic spinal cord express DM-20. Neuropathol Appl Neurobiol 22:188-198.

Durand B, Fero ML, Roberts JM, Raff MC (1998) p27kip1 alters the response of cells to mitogen and is part of a cell-intrinsic timer that arrest the cell cycle and initiates differentiation. Curr Biol 8:431-440.

Ellison JA, de Vellis J (1994) Platelet-derived growth factor receptor is expressed by cells in the early oligodendrocyte lineage. J Neurosci Res 37:116-128.

Finnin MS, Donigian JR, Cohen A, Richon VM, Rifkind RA, Marks PA, Breslow R, Pavletich NP (1999) Structures of a histone deacetylase homologue bound to the TSA and SAHA inhibitors. Nature 401:188-193.

Gard AL, Pfeiffer SE (1993) Glial cell mitogens bFGF and PDGF differentially regulate development of $\mathrm{O} 4+\mathrm{GalC}^{-}$oligodendrocyte progenitors. Dev Biol 159:618-630.

Ghiani C, Gallo V (2001) Inhibition of cyclin E-cyclin-dependent kinase 2 complex formation and activity is associated with cell cycle arrest and withdrawal in oligodendrocyte progenitor cells. J Neurosci 21:1274-1282.

Ghiani CA, Eisen AM, Yuan X, DePinho RA, McBain CJ, Gallo V (1999) Neurotransmitter receptor activation triggers p27(Kip1) and p21(CIP1) accumulation and G1 cell cycle arrest in oligodendrocyte progenitors. Development 126:1077-1090.

Griffith EC, Cowan CW, Greenberg ME (2001) REST acts through multiple deacetylase complexes. Neuron 31:339-340.

Hart IK, Richardson WD, Heldin CH, Westermark B, Raff MC (1989) PDGF receptors on cells of the oligodendrocyte-type-2 astrocyte (O2-A) lineage. Development 105:595-603.

Huang Z, Tang XM, Cambi F (2002) Down-regulation of the retinoblastoma protein $(\mathrm{rb})$ is associated with rat oligodendrocyte differentiation. Mol Cell Neurosci 19:250-262.

Jeong S, Stein A (1994) Micrococcal nuclease digestion of nuclei reveals extended nucleosome ladders having anomalous DNA lengths for chromatin assembled on non-replicating plasmids in transfected cells. Nucleic Acids Res 22:370-375.

Kondo T, Raff M (2000) The Id4 HLH protein and the timing of oligodendrocyte differentiation. EMBO J 19:1998-2007.

Mallon BS, Shick HE, Kidd GJ, Macklin WB (2002) Proteolipid promoter activity distinguishes two populations of NG2-positive cells throughout neonatal cortical development. J Neurosci 22:876-885.

McCarthy KD, de Vellis J (1980) Preparation of separate astroglial and oligodendroglial cell cultures from rat cerebral tissue. J Cell Biol 85:890-902.

Nakashima K, Wiese S, Yanagisawa M, Arakawa H, Kimura N, Hisat- 
sune T, Yoshida K, Kishimoto T, Sendtner M, Taga T (1999) Developmental requirement of gp130 signaling in neuronal survival and astrocyte differentiation. J Neurosci 19:5429-5434.

Noble M, Murray K (1984) Purified astrocytes promote the in vitro division of a bipotential glial progenitor cell. EMBO J 3:2243-2247.

Pfeiffer SE, Warrington AE, Bansal R (1993) The oligodendrocyte and its many cellular processes. Trends Cell Biol 3:191-197.

Raff MC, Williams BP, Miller RH (1984) The in vitro differentiation of a bipotential glial progenitor cell. EMBO J 5:1857-1864.

Rodriguez-Pena A (1999) Oligodendrocyte development and thyroid hormone. J Neurobiol 40:497-512.

Roth SY, Allis CD (1996) Histone acetylation and chromatin assembly: a single escort, multiple dances? Cell 87:5-8.

Schoenherr CJ, Anderson DJ (1995) Silencing is golden: negative regulation in the control of neuronal gene transcription. Curr Opin Neurobiol 5:566-571.

Sowa Y, Orita T, Hiranabe-Minamikawa S, Nakano K, Mizuno T, Nomura H, Sakai T (1999) Histone deacetylase inhibitor activates the p21/WAF1/Cip1 gene promoter through the Sp1 sites. Ann NY Acad Sci 886:195-199.

Struhl K (1998) Histone acetylation and transcriptional regulatory mechanisms. Genes Dev 12:599-606.

Sun Y, Nadal-Vicens M, Misono S, Lin MZ, Zubiaga A, Hua X, Fan G, Greenberg ME (2001) Neurogenin promotes neurogenesis and inhibits glial differentiation by independent mechanisms. Cell 104:365-376.

Svaren J, Horz W (1996) Regulation of gene expression by nucleosomes. Curr Opin Genet Dev 6:164-170.

Tang X-M, Beesley JS, Grinspan JB, Seth P, Kamholz J, Cambi F (1999) Cell cycle arrest induced by ectopic expression of p 27 is not sufficient to promote oligodendrocyte differentiation. J Cell Biochem 76:270-279.

Temple S, Raff MC (1985) Differentiation of a bipotential glial progenitor cell in a single cell microculture. Nature 313:223-225.
Temple S, Raff MC (1986) Clonal analysis of oligodendrocyte development in culture: evidence for a developmental clock that counts cell divisions. Cell 44:773-779.

Tikoo R, Osterhout DJ, Casaccia-Bonnefil P, Preth S, Koff A, Chao M VC (1998) Ectopic expression of p27 in oligodendrocyte progenitors induces growth arrest. J Neurobiol 36:431-440.

Timsit S, Martinez S, Allinquant B, Peyron F, Puelles L, Zalc B (1995) Oligodendrocytes originate in a restricted zone of the embryonic ventral neural tube defined by DM-20 mRNA expression. J Neurosci 15:1012-1024.

Wegner M (2001) Expression of transcription factors during oligodendroglial development. Microsc Res Tech 52:746-752.

Wight PA, Dobretsova A, Macklin WB (1997) Regulation of murine myelin proteolipid protein gene expression. J Neurosci Res 50:917-927.

Xiao H, Hasegawa T, Isobe K (1999) Both Sp1 and Sp3 are responsible for $\mathrm{p} 21$ waf1 promoter activity induced by histone deacetylase inhibitor in NIH3T3 cells. J Cell Biochem 73:291-302.

Yoshida M, Kijima M, Akita M, Beppu T (1990) Potent and specific inhibition of mammalian histone deacetylase both in vivo and in vitro by trichostatin A. J Biol Chem 265:17174-17179.

Yoshida M, Horinouchi S, Beppu T (1995) Trichostatin A and trapoxin: novel chemical probes for the role of histone acetylation in chromatin structure and function. BioEssays 17:423-430.

Zezula J, Casaccia-Bonnefil P, Ezhevsky SA, Osterhout DJ, Lenive JM, Dowdy SF, Chao MV, Koff A (2001) p21cip1 is required for the differentiation of oligodendrocytes independently of cell cycle withdrawal. EMBO J 2:27-34.

Zhang HS, Gavin M, Dahiya A, Postigo AA, Ma D, Luo RX Harbour JW, Dean DC (2000) Exit from G1 and S phase of the cell cycle is regulated by repressor complexes containing HDAC-Rb-hSWI/SNF and Rb-hSWI/SNF. Cell 101:79-89. 